\title{
Thyrotoxicosis with concomitant thyroid cancer
}

\author{
Hao Fu, Lin Cheng, Yuchen Jin and Libo Chen \\ Department of Nuclear Medicine, Shanghai Jiao Tong University Affiliated Sixth People's Hospital, Shanghai, People's Republic of China \\ Correspondence should be addressed to L Chen: Ibchen@sjtu.edu.cn
}

\begin{abstract}
Thyrotoxicosis with concomitant thyroid cancer is rare and poorly recognized, which may result in delayed diagnosis, inappropriate treatment and even poor prognosis. To provide a comprehensive guidance for clinicians, the etiology, pathogenesis, diagnosis and treatment of this challenging setting were systematically reviewed. According to literatures available, the etiologies of thyrotoxicosis with concomitant thyroid cancer were categorized into Graves' disease with concurrent differentiated thyroid cancer (DTC) or medullary thyroid cancer, Marine-Lenhart Syndrome with coexisting DTC, Plummer's disease with concomitant DTC, amiodarone-induced thyrotoxicosis with concomitant DTC, central hyperthyroidism with coexisting DTC, hyperfunctioning metastases of DTC and others. The underlying causal mechanisms linking thyrotoxicosis and thyroid cancer were elucidated. Medical history, biochemical assessments, radioiodine uptake, anatomic and metabolic imaging and ultrasonography-guided fine-needle aspiration combined with pathological examinations were found to be critical for precise diagnosis. Surgery remains a mainstay in both tumor elimination and control of thyrotoxicosis, while anti-thyroid drugs, beta-blockers, 131I, glucocorticoids, plasmapheresis, somatostatin analogs, dopamine agonists, radiation therapy, chemotherapy and tyrosine kinase inhibitors should also be appropriately utilized as needed.
\end{abstract}

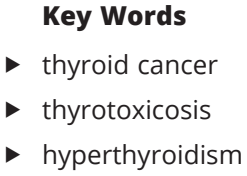

Endocrine-Related Cancer (2019) 26, R395-R413

\section{Introduction}

Thyrotoxicosis, mainly caused by Graves' disease, is a condition that results from inappropriately high thyroid hormone actions in tissues. Although it commonly manifests palpitations, shortness of breath, increased appetite, sweating, heat intolerance, etc. (Gilbert 2017), multiple etiologies and potential therapeutic options may be involved. Besides specific clinical symptoms and signs, elevated triiodothyronine $\left(\mathrm{T}_{3}\right)$ and/or thyroxine $\left(\mathrm{T}_{4}\right)$ as well as suppressed thyroid-stimulating hormone (TSH) facilitate the diagnosis of thyrotoxicosis except central hyperthyroidism, in which TSH is nonsuppressed (Vinagre et al. 2014, Perticone et al. 2015). Although the ratio of total $\mathrm{T}_{3}$ to total $\mathrm{T}_{4}$ can be useful in differential diagnosis (Shigemasa et al. 1987, Carle et al. 2013), in patients with mild or subclinical hyperthyroidism, $\mathrm{T}_{4}$ and/or $\mathrm{T}_{3}$ can be normal, and therefore, measurement of serum TSH with highest sensitivity and specificity, is the most preferred (de Los Santos et al. 1989).

Thyroid carcinoma, however, is usually identified by ultrasonography and then confirmed by ultrasonographyguided fine-needle aspiration (FNA) followed by pathological examinations, which categorize thyroid carcinoma into three groups, DTC, anaplastic thyroid carcinoma (ATC) and medullary thyroid carcinoma (MTC). DTC can be further classified as papillary thyroid carcinoma (PTC), follicular thyroid carcinoma (FTC), Hürthle cell carcinoma (HCC) and poorly differentiated thyroid carcinoma. With globally rising incidence, thyroid carcinoma has attracted much more concern than before.

In theory, thyrotoxicosis with suppressed TSH should lead to a lower incidence of thyroid cancer than that observed in euthyroid patients 
(Fiore \& Vitti 2012). In practice, thyroid cancer is typically less efficient in iodine uptake and thyroxine synthesis than normal parenchymal, and most patients with thyroid cancer present with euthyroid or clinical/subclinical hypothyroidism (Kunawudhi et al. 2016). However, an increasing number of studies have demonstrated that more attention should be paid to the management of thyrotoxicosis with concurrent thyroid cancer since the first case of hyperfunctioning thyroid cancer metastases was successfully treated with radioactive iodine (131I) (Seidlin et al. 1946). A comprehensive guidance for the clinical management of thyrotoxicosis combined with the neoplastic disease is greatly needed, owing to that misdiagnosis or inappropriate treatment may worsen the prognosis if the etiology and pathogenesis of synchronous thyrotoxicosis in patients with thyroid cancer are not sufficiently recognized (Cerletty \& Listwan 1979).

However, there is no extant systematic review or consensus dedicated to thyrotoxicosis with concurrent thyroid cancer, possibly due to its low morbidity and management difficulties. We, therefore, performed a comprehensive PubMed search using the combined terms of 'thyroid cancer' and 'thyrotoxicosis' or 'hyperthyroidism', yielding 762 and 4255 articles prior to December 31, 2018, respectively. The mechanism, diagnosis and treatment according to the etiologies of thyrotoxicosis, including Graves' disease, Marine-Lenhart Syndrome (MLS), Plummer's disease, amiodaroneinduced thyrotoxicosis (AIT), central hyperthyroidism, hyperfunctioning metastases of DTC and others, were discussed in detail. Moreover, refined diagnostic schemes and practical treatment options for each condition were recommended as well.

\section{Graves' disease with concomitant thyroid cancer}

Graves' disease is an autoimmune disease that results from stimulation of the TSH receptor (TSHR) by thyrotropin receptor antibodies (TRAb). The prevalence of concomitant thyroid cancer occurring in patients with Graves' disease reach up to 17\% (Weber et al. 2006). Although PTC is the most frequently reported histologic type happened in Graves' disease, MTC with concomitant Graves' disease has also been reported (Habra et al. 2004), and other clinicopathological characteristics and survival features of thyroid cancer associated with Graves' disease or euthyroidism remain controversial among studies (Pellegriti et al. 1998, Yano et al. 2007,
Pazaitou-Panayiotou et al. 2012). MLS, defined as concomitant occurrence of autonomously functioning thyroid nodule (AFTN) and Graves' disease (Marine \& Lenhart 1911), has the possibility of coexisting DTC as well (Scherer et al. 2013). PTC and FTC occurred in MLS only reported by several cases by far (Scherer et al. 2013, Sharma 2017).

\section{Mechanism}

TRAb, similar to TSH, exhibits agonistic activity to TSHR, leading to the secretion of thyroid hormones and thyrotoxicosis, which is independent of the hypothalamic-pituitary-thyroid axis. In addition, TRAb might play a role in stimulating DTC growth because DTC cells express TSHR like normal thyroid cells do (Preece et al. 2014). Furthermore, TRAb stimulates invasiveness and angiogenesis of DTC by upregulating vascular endothelial growth factor, placenta growth factor, and their receptors via the same signaling pathways as TSH-induced cell activation and growth (Filetti et al. 1988, Mazzaferri 1990). In addition, TSH plays an important role in regulating DTC cell growth, which is incorporated by the insulinlike growth factor (IGF) system (Malaguarnera et al. 2012). Considering the important functional similarities between TSH and TRAb, IGF-1 could also affect the growth of DTC in patients with Graves' disease.

MTC sometimes associates with multiple endocrine neoplasia (MEN) syndromes, however, none of the reported cases of Graves' disease associated with MTC was finally diagnosed as MEN (Habra et al. 2004), and the mechanism of Graves' disease associated with MTC is still unclear.

DTCs found in or out of AFTN in MLS are really rare events (Valenti et al. 1999, Scherer et al. 2013, Sharma 2017, Lombardi et al. 2018). The DTC happened in MLS may be related to the stimulation of TRAb or gene mutation such as BRAF ${ }^{\mathrm{V} 600 \mathrm{E}}$ (Scherer et al. 2013).

\section{Diagnosis}

Increased TRAb is helpful in distinguishing Graves' disease from other etiologies of thyrotoxicosis, except mild Graves' disease, in which TRAb can be still negative (Carle et al. 2013). Radioactive iodine uptake (RAIU) is an alternative testing, which is usually elevated, unless there has been a recent exposure to iodine such as radiocontrast or amiodarone. Thyroid scan displays with diffuse radioisotope uptake, whereas the tumor is generally low uptake as a 'cold' nodule (Basharat et al. 2011, (c) 2019 Society for Endocrinology Published by Bioscientifica Ltd. Printed in Great Britain 
Elnaggar et al. 2018). In addition, ultrasonography may be particularly useful through providing representative information of Graves' disease with diffuse, bilateral or isthmic goiter, heterogeneous and hypoechogenicity parenchyma and hypervascularization with the classical aspect so called 'thyroid inferno', and describing the characteristics of malignant thyroid nodule, including taller than wide shape, hypoechogenicity, irregular margins, calcifications, vascularity and extrathyroidal extension (Alzahrani et al. 2012, Bogazzi et al. 2012, Goichot et al. 2018). In such situations, ultrasonography is also the primary diagnostic modality available for a guided FNA cytology/biopsy (FNAC/B) of nodules (Haugen et al. 2016).

For MTC with concurrent Graves' disease, beyond the above indicators of Graves' disease and malignant nodule (Kim et al. 2017), the diagnosis can be facilitated by testing serum calcitonin and carcinoembryonic antigen with superior efficacy to ultrasonography FNAB (Hahm et al. 2001). In addition, computed tomography (CT) of the chest and abdomen can provide evidences of cervical lymphadenopathy, pulmonary or hepatic metastases.

MLS with coexisting DTC is characterized by increased TRAb and RAIU, differentiating from Plummer's disease (Sharma 2017). Tumor manifests hypoecho in ultrasonography with or without microcalcification and presents 'hot' nodule in thyroid scan with comparatively lower but not suppressed uptake of the rest parenchymal tissue. If ultrasonography indicates malignant tendency of the nodule, FNAC is essential to confirm the diagnosis (Scherer et al. 2013, Sharma 2017).

\section{Treatment}

Surgery is the most appropriate treatment for Graves' disease with concomitant DTC. However, surgery for Graves' disease is recognized to be more challenging due to the increased vascularity of the thyroid gland and has been reported to be associated with higher rates of complications compared with surgery for other benign thyroid conditions (Karamanakos et al. 2010). Since thyroid storm may be precipitated by the stress of surgery, anesthesia or thyroid manipulation, pretreatment with anti-thyroid drugs (ATDs) with or without beta-adrenergic blockade is recommended (Ross et al. 2016).

Propylthiouracil (PTU) is preferred during the first trimester of pregnancy, for treatment of thyroid storm, and in patients with minor reactions to methimazole (MMI). Apart from that, MMI should be used in virtually every patient who chooses ATDs therapy for Graves' disease.
Compared with MMI, PTU can control thyrotoxicosis faster because it not only suppresses thyroid hormone synthesis by inhibiting thyroperoxidase, but also restrains the conversion of $\mathrm{T}_{4}$ to $\mathrm{T}_{3}$.

Initial daily doses of $10-30 \mathrm{mg}$ are used to restore euthyroidism at the start of MMI therapy, and the dose can then be titrated down to a maintenance level; while PTU is usually administered $50-150 \mathrm{mg} 2$ or 3 times daily due to its shorter duration of action. During treatment with ATDs tailored to the individual patient, clinicians should monitor blood and hepatic function closely due to the possible side effects of ATDs.

Potassium iodine has been used as a beneficial adjunct to ATDs therapy for Graves' disease, because it attenuates organification and release of thyroid hormones as well as thyroid vascularity and intraoperative blood loss during thyroidectomy (Calissendorff \& Falhammar 2017). Compared with MMI alone, potassium iodine together with MMI results in better control of thyrotoxicosis and fewer adverse reactions. In addition, corticosteroids, and potentially cholestyramine can be used to rapidly prepare for emergent surgery (Panzer et al. 2004).

Although surgical procedures for DTC vary depending upon the clinical pathological characteristics of the tumor, near-total or total thyroidectomy is now well established as the choice in patients undergoing surgery for Graves' disease to prevent the recurrence (Barakate et al. 2002, Sundaresh et al. 2017). In addition, cervical lymph nodes are dissected when macroscopically involved or in the presence of extensive invasion of central nodes (Pellegriti et al. 2013). For patients with unresectable distant metastases from DTC, ${ }^{131}$ I therapy is executed subsequently.

For Graves' disease with concomitant MTC, total thyroidectomy under biochemical euthyroidism achieved by administration of ATDs and beta-blockers is appropriate (Habra et al. 2004). If the evidence of extrathyroidal tumor extension and metastases existed, adjuvant therapy such as radiation therapy or molecular targeted therapy would be needed (Brierley et al. 1996, Solomon \& Rischin 2012). The treatment strategies for MLS with concomitant DTC is similar to Graves' disease with coexisting MTC, and subsequent ${ }^{131} \mathrm{I}$ administration is recommended if necessary (Scherer et al. 2013, Uludag et al. 2016).

\section{Plummer's disease with concomitant DTC}

Plummer's disease, which is also known as toxic nodular or toxic multinodular goiter (TMNG) commonly happened in iodine deficient regions, is an active multinodular goiter 
associated with thyrotoxicosis (Kang et al. 2002, Porterfield et al. 2008). The incidence of DTC is higher than expected in Plummer's disease (18.3 vs 3.0\%) (Smith et al. 2013). The predominant pathological pattern is PTC, follicular variant of papillary thyroid cancer (FVPTC) and FTC are also involved (Ngalob \& Isip-Tan 2013, Smith et al. 2013).

\section{Mechanism}

A long period of iodine deficiency leads to $\mathrm{T}_{4}$ decreasing, which in turn increases TSH and induces thyroid follicular cell hyperplasia. Besides, thiocyanate from smoking exerts inhibitory effect on iodine uptake and organification (Hegedüs et al. 2016). All the above mechanisms account for the appearance of multinodular goiter (MNG). The conversion of MNG to TMNG is attributed to constitutive activation of the cyclic adenosine monophosphate (cAMP) signaling pathway by mutation of TSHR and $\mathrm{G}_{\mathrm{s}} \alpha$ protein (Krohn et al. 2005). In addition, the extracellular growth factors, such as transforming growth factor $\beta$ and IGF-1, stimulate growth and dedifferentiation of thyroid epithelial cells, leading to tumorigenesis (Krohn et al. 2005, Hegedüs et al. 2016).

\section{Diagnosis}

Unlike Graves' disease, TRAb in Plummer's disease is negative. Ultrasonography detects solid thyroid nodule with intranodular hypervascularization (Kurita et al. 2008). CT provides not only the information of nodule size, calcifications and compression of the adjacent tissue, but also the metastases of lymph nodes, lungs and bones. Magnetic resonance imaging (MRI) is thought to be more precise than CT in the anatomo-topographic evaluation of the substernal goiter (Porterfield et al. 2008). Thyroid scan with $99 \mathrm{~m}$ Tc-pertechnetate presents functioning thyroid nodule with minimal uptake of the rest gland (Ngalob \& Isip-Tan 2013). Although 'hot' nodule is generally considered as benign, a higher incidental cancer rate than expected can be found in patients with Plummer's disease compared to historical reports (Smith et al. 2013). Hence, if ultrasonography suggests malignant signs such as calcifications and vascularity or metastases, FNAB of primary nodule or metastases should be recommended (Ngalob \& Isip-Tan 2013).

\section{Treatment}

If patient has a perspicuous diagnosis of Plummer's disease associated with DTC, surgery is the first choice because it can not only resect the primary tumor and metastases, but resolve compression and thyrotoxicosis symptoms rapidly as well. Biochemical euthyroidism achievement with ATDs before surgery and subsequent ${ }^{131}{ }^{13}$ therapy for the unresectable metastases are also necessary (Ngalob \& Isip-Tan 2013).

\section{AIT with concurrent DTC}

Amiodarone is an antiarrhythmic medication used to treat ventricular tachycardia and fibrillation or severe congestive heart failure. AIT occurs in up to $18 \%$ patients under amiodarone therapy due to high iodine content deriving from amiodarone in patients with underlying thyroid autonomy in a nodular goiter or Graves' disease (AIT1) and destructive thyroiditis raising from direct toxicity of amiodarone to follicular cells (AIT2) (Bogazzi et al. 2001). The pathological patterns of DTC in AIT include PTC and FVPTC, which usually occurred in elderly men (Cattaneo 2000, Saad et al. 2004, Mackie \& Shulkin 2005, Inaba et al. 2012).

\section{Mechanism}

Thyrotoxicosis, including AIT, is positively related to the tumorigenesis of thyroid cancer (Stocker \& Burch 2003, Preece et al. 2014). Thyroid cancer has been observed to occur more frequently in rats administered amiodarone, owing to amplified radiation toxicity (Inaba et al. 2012). In addition, investigators have demonstrated that amiodarone is directly carcinogenic to human (Su et al. 2013).

\section{Diagnosis}

If thyroid nodules are found in patients with a long history of amiodarone administration, clinicians should be highly vigilant for the malignant possibility of the nodules. The absolute levels of free $\mathrm{T}_{4}\left(\mathrm{FT}_{4}\right)$ and free $\mathrm{T}_{3}\left(\mathrm{FT}_{3}\right)$ at presentation have no discriminatory value between AIT1 and AIT2, although they tend to be higher in AIT2. Thyroperoxidase antibody (TPOAb), thyroglobulin antibody and TRAb are often positive in AIT1 but negative in AIT2, although their presence does not necessarily allow a diagnosis of AIT1 (Cattaneo 2000, Saad et al. 2004, Franklyn \& Gammage 2007, Inaba et al. 2012). Interleukin-6 (IL-6) appears to be a better marker for thyroid gland destruction and is markedly elevated in AIT2 (Bartalena et al. 1994). However, falsely low IL-6 levels (c) 2019 Society for Endocrinology Published by Bioscientifica Ltd. Printed in Great Britain 
are often encountered in AIT2, limiting its usefulness. In addition, several preexisting disorders of the thyroid such as Graves' disease can give rise to high IL-6 levels. Therefore, at present, the role of IL- 6 in differentiating type 1 and type 2 AIT remains unclear (Sudheer Ahamed $\&$ Mathew 2009).

RAIU is usually reduced or nil in patients with AIT2 and ranges from low-normal to an increased uptake in those with AIT1 (Bartalena et al. 2018). Before performing RAIU, patients are needed to exclude the influence of iodine, which could induce false-negative or -positive results. In addition, ${ }^{99 \mathrm{mTc}}$ sestamibi (99mTc-MIBI) scans have been reported to be helpful in differentiating between the two principal types of AIT, with normal or increased uptake in AIT1 and decreased uptake in AIT2 due to the destruction of thyroid follicular cells by amiodarone (Piga et al. 2008, Elnaggar et al. 2018).

In thyroid ultrasonography, goiter or nodules are generally found in AIT1 but not in AIT2; and AIT1 usually presents as hyperechoic parenchyma, while AIT2 displays hypoechogenic. Doppler sonography also provides a noninvasive, real-time assessment of thyroid vascularity as well as nodules, and is helpful in demonstrating the destructive nature of AIT2 without parenchymal hypervascularity (Alzahrani et al. 2012).

\section{Treatment}

AIT is frequently resistant to ATDs, increasing morbidity and mortality (Yiu et al. 2009). It is suggested to halt amiodarone during the management of AIT to improve the efficacy of anti-thyroid treatment (Bogazzi et al. 2010). However, arrhythmias in cardiac patients increase the risk of surgery and anesthesia, and amiodarone remains the only option and needs to be continued or re-introduced in resistant tachyarrhythmia, especially in patients with heart failure. In addition, amiodarone with a half-life of up to 100 days, is accumulated within the adipose tissue and should be interrupted for at least 6 months to be eliminated (Bogazzi et al. 2010). Moreover, despite interruption of amiodarone administration, spontaneous remission of thyrotoxicosis is rare (Elnaggar et al. 2018). Thus, one can suggest that its interruption or continuation might not influence AIT management. Presently, amiodarone interruption in AIT1 is recommended to improve the response to ATDs, but in patients with AIT2, this is not compulsory (Maqdasy et al. 2018).

It is important to distinguish between both types of AIT as the therapy differs for each. AIT1 is primarily treated using ATDs such as thionamides (carbimazole, methimazole or propylthiouracil) to suppress excess hormone synthesis. Long durations and large doses of thionamide treatment $(40-60 \mathrm{mg}$ /day of methimazole or equivalent doses of propylthiouracil) may be necessary to establish euthyroidism even if amiodarone is halted (Bogazzi et al. 2010). Patients on thionamides should be cautious about the serious side effect, including bone marrow suppression and the possible symptoms of sore throat, mouth ulcers and febrile illness. To increase the sensitivity and response of the thyroid gland to thionamides, a 4- to 6-week course of potassium perchlorate at doses not exceeding $1 \mathrm{~g} /$ day, which could decrease the entry of iodine into the thyroid and competitively inhibits thyroid iodine uptake, has been used (Wiersinga 2010, Ahmed et al. 2011, Bartalena et al. 2018).

AIT2 is usually treated with glucocorticoids for their anti-inflammatory and membrane-stabilizing effect. The proposed initial dose is $40-60 \mathrm{mg} /$ day of prednisone (or equivalent doses of other glucocorticoids), which is then tapered based on clinical and/or biochemical euthyroidism (Narayana et al. 2011). Another agent that has been tried in the treatment of AIT2 is lithium carbonate, which inhibits thyroid hormone secretion, but this is not backed by adequate scientific evidence.

In fact, some patients manifest a 'mixed type' AIT in which single treatment is insufficient, and a combination of thioamides, perchlorate and glucocorticoids is necessary to control thyrotoxicosis (Maqdasy et al. 2018). In patients with life-threatening thyrotoxicosis or in individuals refractory to medical treatment, plasmapheresis may be used to decrease the perioperative risks associated with thyroidectomy by rapidly restoring a clinical and biochemical euthyroid state (Tonnelier et al. 2017).

Surgery is a valid therapy for patients with AIT accompanied by DTC and for patients with severe symptoms that are resistant to combined therapeutic strategies or in cases of drug contraindications (Zhu et al. 2016, Tonnelier et al. 2017). In fact, thyroidectomy feasibly yields in an immediate reversal of AIT with rapid resolution of symptoms (Houghton et al. 2004, Saad et al. 2004). As remnant tissue poses a risk for recurrent or persistent thyrotoxicosis, total thyroidectomy is recommended (Williams \& Lo Gerfo 2002, Kaderli et al. 2016). Some authors performed thyroidectomy using local or general anesthesia in critically ill patients with AIT (Williams \& Lo Gerfo 2002, Kaderli et al. 2016), which showed no increased risk for morbidity or mortality. In contrast, a series of 34 patients from Mayo Clinic demonstrated elevated morbidity and mortality (Houghton et al. 2004). 
Therefore, if at all possible, thyroid hormones should be normalized before surgery to minimize the peri-operative complications.

\section{Central hyperthyroidism with coexisting DTC}

Central hyperthyroidism, which has been defined as secondary hyperthyroidism, is possibly associated with DTC. Central hyperthyroidism with coexisting DTC can be divided into two categories: TSH-secreting pituitary adenoma (TSHoma) with concomitant DTC and pituitary resistance to thyroid hormone (PRTH) with coexisting DTC. Both of them present symptoms and signs of hyperthyroidism with nonsuppressed TSH. TSHoma is a very rare disorder, which accounts for about $0.5-3 \%$ of all pituitary adenomas (Perticone et al. 2015). PRTH induced thyrotoxicosis mainly involves the heart and brain. In the last years, several cases of central hyperthyroidism associated with DTC have been reported. The pathological patterns of DTC occurring in central hyperthyroidism include PTC and FTC (Vinagre et al. 2014, Perticone et al. 2015).

\section{Mechanism}

So far, the pathogenesis of TSHoma is unclear. Possible mechanisms involve over-expression of Pit- 1 gene and the basic fibroblast growth factor as well as posttranscriptional defects and function alterations in thyroid hormone receptor (TR) of tumoral thyrotropes (Beck-Peccoz et al. 2009).

The revealed pathogenesis of PRTH includes mutations in the thyroid hormone transporters (organic anion transporting polypeptide 14 and monocarboxylate transporter 8), the restricted expression of the deiodinase type 2, and the disruption of specific TRb2 contact mechanisms (Suzuki et al. 2011).

As described earlier, a prolonged period of unregulated and inappropriately high levels of TSH induced by TSHoma or PRTH may have a stimulatory effect on thyroid neoplasia (Vinagre et al. 2014, Perticone et al. 2015).

\section{Diagnosis}

The confounding factors, such as antibodies against TSH or thyroid hormones as well as abnormal forms of albumin or transthyretin, should be excluded before confirming the diagnosis of central hyperthyroidism (BeckPeccoz et al. 2009, Amlashi \& Tritos 2016). To exclude thyroid diseases, TRAb and TPOAb are of value, and they are generally negative in central hyperthyroidism (Vinagre et al. 2014, Perticone et al. 2015).

There are no significant differences in TSH and free thyroid hormone levels between patients with TSHoma and those with PRTH, making differential diagnosis difficult. Moreover, although pituitary hypersecretion of $\alpha$-glycoprotein ( $\alpha$-GSU) and elevated $\alpha$-GSU/TSH ratio are detected in most TSHoma patients, it is more frequently normal in microadenomas than in macroadenomas (Ness-Abramof et al. 2007, Yamada et al. 2014). Sometimes, the diagnosis of TSHoma can be facilitated by the presence of neurological symptoms such as visual defects and headache or clinical characteristics of concomitant hypersecretion of other pituitary hormones such as acromegaly and amenorrhoea/galactorrhoea (Kiatpanabhikul et al. 2017). In addition, carboxyterminal crosslinked telopeptide of type I collagen and sexhormone-binding globulin are increased in patients with TSHoma but normal in patients with PRTH (BeckPeccoz et al. 2009). Furthermore, the findings of similar biochemical data in relatives definitely indicate the diagnosis of PRTH, since familial cases of TSHoma have not been documented (Beck-Peccoz et al. 2009).

It is proposed that dynamic tests are of value to make a distinction between TSHoma and PRTH. $\mathrm{T}_{3}$ suppression test is most sensitive and specific to assess the presence of TSHoma with no inhibition of TSH secretion compared with PRTH. Of note, this test is contraindicated in elderly patients or patients with coronary heart disease. In addition, a blunted TSH response to the thyrotropinreleasing hormone (TRH) stimulation test has also been seen in most patients with TSHoma, in contrast to PRTH patients who generally show a rise in TSH levels after TRH administration. On the contrary, increased $\alpha$-GSU after TRH test is positive in TSHoma but negative in PRTH (Tjornstrand \& Nystrom 2017). Besides, longacting somatostatin analogs (SSAs) has been proposed as a distinguishing mean between TSHoma and PRTH, owing to that $\mathrm{FT}_{4}$ and $\mathrm{FT}_{3}$ significantly reduce in patients with TSHoma but not in those with PRTH after SSAs administration (Mannavola et al. 2005).

Hypophyseal mass with suprasellar extension at MRI or CT scan strongly supports the diagnosis of TSHoma. However, it may be difficult to distinguish TSHoma from PRTH if the tumor was very small or empty sella. Pituitary scintigraphy with radiolabelled octreotide has also been shown to successfully localize TSHoma expressing somatostatin receptors. Unfortunately, the specificity of octreotide scan is low in both secreting and https://erc bioscientifica.com

https://doi.org/10.1530/ERC-19-0129 (c) 2019 Society for Endocrinology Published by Bioscientifica Ltd. Printed in Great Britain 
non-secreting pituitary mass (Losa et al. 1997, Amlashi \& Tritos 2016). Positron emission tomography/computed tomography (PET/CT) of gallium-labeled SSAs has been increasingly used in the evaluation of neuroendocrine tumors with successful results in diagnosing ectopic pituitary adenoma (Naswa et al. 2012, Yang et al. 2017). The primary thyroid cancer associated with central hyperthyroidism presents as intranodular hypoecho and vascularization in ultrasonography and 'cold' nodule in thyroid scan. The nodule FNAB will be of value for diagnosing thyroid cancer (Paragliola et al. 2011, Perticone et al. 2015).

\section{Treatment}

Administrating SSAs, ATDs and beta-blockers before surgery can control thyrotoxicosis, which reduces the risk during surgery (Beck-Peccoz et al. 2009). The optimal surgery strategy in patients of TSHoma with coexistent DTC has not been established (Calle-Pascual et al. 1991, Kishida et al. 2000, Perticone et al. 2015). Thyroid surgery is performed before pituitary adenomectomy in some cases, even if it could lead to a progression of TSHoma (Calle-Pascual et al. 1991, Perticone et al. 2015). On the contrary, performing pituitary adenomectomy before thyroidectomy may avoid a theoretically possible growth of the TSHoma and remove a stimulus for DTC progression (Kishida et al. 2000). Another reason for this strategy is that performing pituitary surgery first could be helpful to control thyrotoxicosis as well as neurological symptoms induced by a large and/or invasive TSHoma quickly and effectively. Nevertheless, the therapeutic strategy should be individualized for every single patient, taking into account all the relevant associated comorbidities.

For PRTH patients with concomitant DTC, thyroidectomy is performed to remove the primary neoplasm. If patients have thyrotoxicosis, PTU is preferred because it inhibits deiodinase activity, which is expected to reduce the intracellular content of $T_{3}$ in peripheral tissues. The levothyroxine therapy should be conducted considering the clinical condition of these patients and imitating as much as possible the preoperative hormonal pattern for serum $T_{4}$ and $T_{3}$ even if optimal TSH suppression cannot be achieved (Paragliola et al. 2011). Other drugs of interest which can suppress TSH secretion include triiodothyroacetic acid and dopamine agonists (Aguilar Diosdado et al. 1991, Dulgeroff et al. 1992).

\section{Hyperfunctioning metastases of DTC}

Patients with thyroid cancer are generally clinically euthyroid, and the cancer itself is relatively hypofunctional compared to normal thyroid tissue. Hyperfunctioning metastases of DTC, however, occurs more frequently than previously thought. Although most hyperfunctioning metastases are FTC-derived, metastases from PTC can also induce thyrotoxicosis (Danilovic et al. 2015, Biyi et al. 2016). The major sites of hyperfunctioning metastases are pulmonary and bone (Haq et al. 2007, Nishihara et al. 2010, Biyi et al. 2016), and the rare metastases site of the liver was also reported (Takano et al. 2006, Kunawudhi et al. 2016). According to the study of Qiu, $0.71 \%$ DTC patients present with hyperfunctioning metastases, and the 10-year survival rate of patients with hyperfunctioning metastases was $65.79 \%$, patients younger than 45 years at occurrence of distant metastases, those with only lung metastases, and patients with PTC had better prognoses (Qiu et al. 2015).

\section{Mechanism}

Iodine-induced thyrotoxicosis due to an underlying defect in intrathyroidal iodine regulation, which is referred to as Jöd-Basedow phenomenon, may also exist in DTC metastases (Lorberboym \& Mechanick 1996, van Der Molen et al. 2004, Mackie \& Shulkin 2005).

As described earlier, DTC cells are derived from thyroid follicular cell, and express TSHR as normal thyroid cells do. The TSHR in metastatic DTC, then, acts as an antigen of TRAb, and the TRAb, in turn, stimulates the metastases to produce thyroid hormones (Yoshimura Noh et al. 1997). In addition, the presence of a base substitution at codon 633 in exon 10 of the TSHR gene in thyroid cancer cells can constitutively activate the cAMP cascade and thereby play a role in cancer hyperfunction (Russo et al. 1997). Another possibility is that cancerous thyroid tissue itself is capable of causing overproduction of thyroid hormones. In cases of metastases that induce thyrotoxicosis, metastatic tumors are usually bulky, suggesting that a large mass of cancerous thyroid tissue is necessary to overproduce thyroid hormone (Sundaraiya et al. 2009, Tan et al. 2009).

Generally, iodothyronine deiodinases are expressed in various normal organs or benign thyroid nodules, but low expression in PTC (Bianco et al. 2002, de Souza Meyer et al. 2005). Whereas some cases of FTC with multiple large metastases demonstrated a decrease in $\mathrm{FT}_{4}$ accompanied 
by an increase in $\mathrm{FT}_{3}$, resulting in $\mathrm{T}_{3}$ thyrotoxicosis, which may be due to high activities of deiodinases in massive metastatic follicular cancers (Takano et al. 2006, Miyauchi et al. 2008). Recently, this mechanism has been further confirmed by molecular targeted therapy of radioiodine refractory metastases from FTC, which demonstrated that lenvatinib and sorafenib could rapidly control thyrotoxicosis by inhibiting D1 and/or D2 activity (Danilovic et al. 2015).

\section{Diagnosis}

Measurement of serum thyroglobulin levels is important to monitor DTC metastases, which are commonly located in lung, bone and liver (Miyauchi et al. 2008, Tan et al. 2009). Although chest and abdominal CT, MRI or ${ }^{18}$ F-fluorodeoxyglucose (18F-FDG) PET/CT have been used to rule out the possibility of metastases from other organs, metastases biopsy accompanied by pathological examination is most reliable to verify the origin from thyroid.

In patients with hyperfunctioning DTC metastases, elevated serum thyroid hormones and suppressed TSH are usually found. Interestingly, metastatic FTC commonly presents $\mathrm{T}_{3}$ predominant (Rosario et al. 2005, Takano et al. 2006). Certain criteria should be met to reach a diagnosis of thyrotoxicosis due to the overproduction of hormones by metastatic tissue: (a) the exclusion of hyperfunctioning thyroid goiter; (b) the demonstration of uptake function of metastatic lesion; (c) failure of thyrotoxicosis to resolve after adequate thyroidectomy and (d) thyroid hormones levels still higher than normal without excessive exogenous levothyroxine intake after thyroidectomy.

According to the above mechanisms of hyperfunctioning DTC metastases, several etiologic diagnoses of thyrotoxicosis may be involved including iodine-containing compounds, DTC metastases per se and/or via TRAb and deiodinases. If thyrotoxicosis happened in patients with DTC metastases who received an imageologic examination or amiodarone due to cardiac disorder recently, the diagnosis of iodine-containing compound induced thyrotoxicosis in DTC metastases should be firstly considered. Otherwise, an elevated TRAb level supports the diagnosis of TRAb-induced thyrotoxicosis in patients with DTC metastases. To date, thyrotoxicosis in DTC metastases caused by deiodinases is difficult, since the measurement of deiodinases activity is not readily available.

The hyperfunctioning metastases of DTC generally are well differentiated, displaying excellent
99mTc-pertechnetate and 131I uptake (Chantadisai \& Kingpetch 2014). As we have demonstrated previously, 99mTc-pertechnetate whole-body scan should be recommended for diagnoses as well as predicting the efficacy of 131I therapy (Liu et al. 2017). Figure 1 shows practical management procedures of a representative case with hyperfunctioning DTC metastases.

\section{Treatment}

The therapy for DTC with hyperfunctioning metastases is aimed at treating both the thyrotoxicosis and the neoplastic disease itself, as both are major causes of morbidity and mortality. Treatment of thyrotoxicosis with ATDs is often temporarily effective, whereas normalization of hormonal values and prompt clinical recovery can usually be achieved by ${ }^{131}$ I therapy after total thyroidectomy (Salvatori et al. 1998) (Fig. 1).

Before 131I treatment of metastases, patients are advised to undergo total or completion thyroidectomy to remove possible lesion(s) and eliminate the interference of thyroid gland when undergoing 131I treatment as well as avoid complications caused by destruction of excessive gland (Tan et al. 2009, Nishihara et al. 2010, Biyi et al. 2016). In addition, surgical debulking can be performed on any large and accessible metastatic lesions, which alleviates thyrotoxicosis to a certain extent (Geliebter et al. 2017). For the hyperfunctioning metastases, thyrotoxicosis can be alleviated with 131I therapy despite a persistently low TSH level (Biyi et al. 2016). In the study by Kunawudhi and colleagues (Kunawudhi et al. 2016), the patient was injected with recombination human TSH (rhTSH) before 131I therapy. According to the American Thyroid Association guidelines for the treatment of hyperthyroidism, however, rhTSH should be avoided in these patients (Ross et al. 2016).

Based on previous studies, the prescribed activity of ${ }^{131}$ I to treat hyperfunctioning metastases of DTC varies from $13 \mathrm{mCi}$ to $200 \mathrm{mCi}$ (Tan et al. 2009, Nishihara et al. 2010, Kunawudhi et al. 2016). Although there is no clear criterion for the dose of ${ }^{131}$ I in treatment of functional metastases, it should be noted that high doses of ${ }^{131}$ I could cause a large amount of tumor cell destruction, releasing a burst of thyroid hormones and causing thyrotoxic storm if the patients were not prepared adequately before and after ${ }^{131}$ I treatment.

To avoid the occurrence of thyrotoxic storm that could become more frequent in seriously ill patients, glucocorticoids and ATDs (prefer PTU) should be used prior to surgery and 131I treatment, as well as during 131I
C) 2019 Society for Endocrinology Published by Bioscientifica Ltd. Printed in Great Britain 


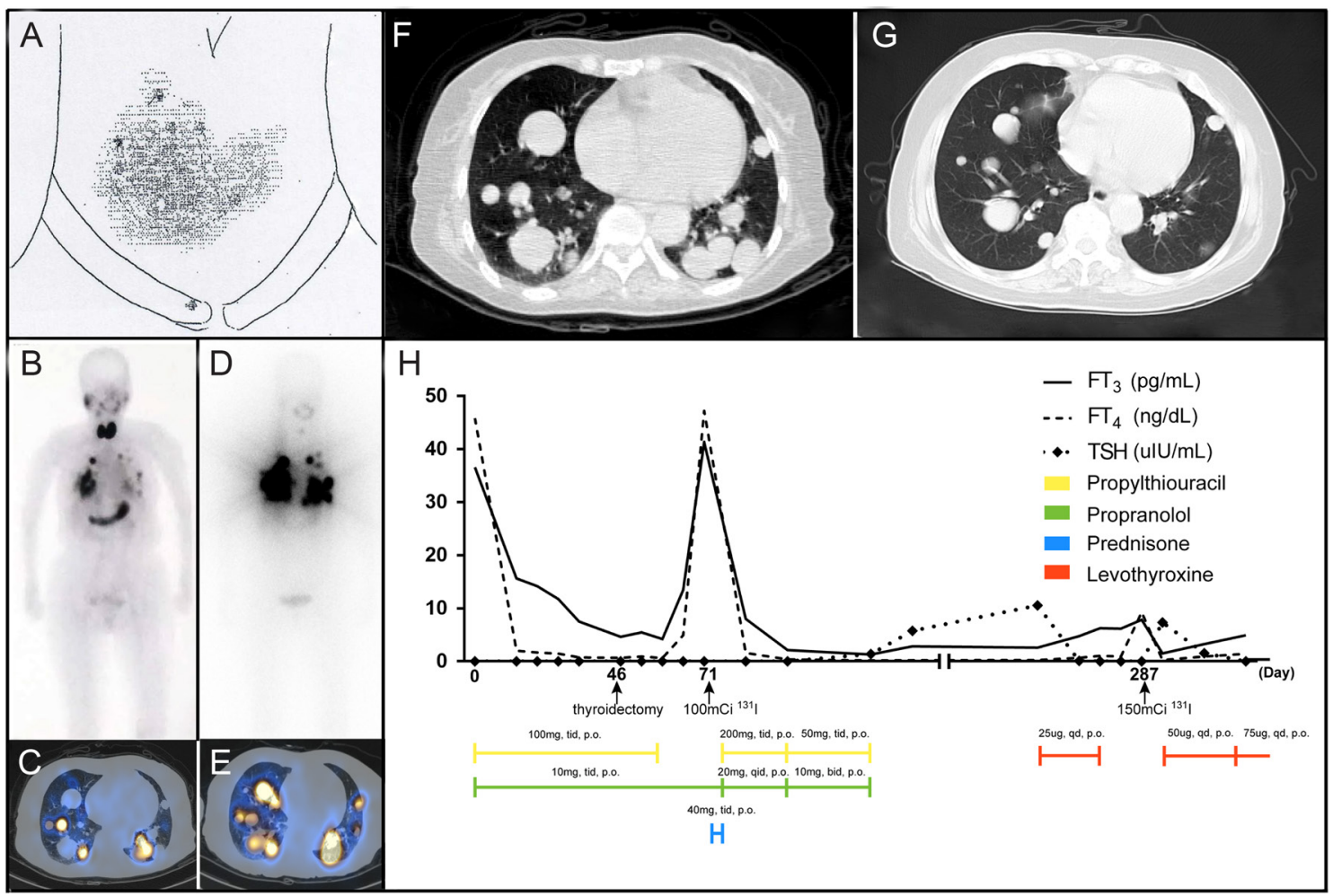

Figure 1

Representative diagnosis and treatment procedures of a case with hyperfunctioning metastases of differentiated thyroid cancer. A 67-year-old female, who had received 'thyroid adenoma' resection due to compression symptoms and a 'hot' mass in thyroid radioiodine scan (A) with normal thyroid hormones and radioactive iodine uptake (RAIU) 24 years before, was referred to our hospital for further management of severe weight loss and heart failure. Since robustly enhanced thyroid hormones (T3-predoninant) and undetectable TSH but normal RAIU were identified, 99mTc-pertechnetate whole-body scan (WBS) was performed, which displayed abnormal uptake in chest with thyroid remnant accumulation (B). 99mTC-pertechnetate SPECT/CT was then immediately added, which revealed multiple 99mTc-avid pulmonary nodules suggesting metastases from DTC (C). Six weeks after the beginning of the medications of propylthiouracil (PTU, $100 \mathrm{mg}$, tid, p.o.) and propranolol (10 mg, tid, p.o.) when symptoms and signs relieved, complete thyroidectomy was performed with the above medications sustained for another 2 weeks. After 2 weeks of withdrawal of PTU only, the levels of thyroid hormones increased significantly, demonstrating the diagnosis of hyperfunctioning DTC metastases, a $3.7 \mathrm{GBq}(100 \mathrm{mCi})$ of 131 I was administered accompanied by prednisone ( $40 \mathrm{mg}$, tid, p.o.) for 3 days and then switched to PTU ( $200 \mathrm{mg}$, tid, p.o.) and propranolol (20 mg, qid, p.o.). Post therapeutic WBS combined with ${ }^{131}$ I SPECT/CT exhibited robust 131 I accumulation in the pulmonary lesions (D, 131| WBS; E, 131 I SPECT/CT fusion imaging). Definitive therapeutic effects were verified by shrinkage of metastases, relief of heart failure (F, computed tomography before initial ${ }^{131}$ I therapy; $G$, computed tomography six month post initial ${ }^{131}$ l therapy), decreasing levels of thyroid hormones and subsequent levothyroxine replacement $(H)$, warranting more courses of ${ }^{131}$ therapy. A full colour version of this figure is available at https://doi.org/10.1530/ERC-19-0129.

treatment via inhibiting thyroid hormone synthesis and peripheral conversion of $\mathrm{T}_{4}$ to $\mathrm{T}_{3}$ (Cerletty \& Listwan 1979). The recommended doses of glucocorticoids are $300 \mathrm{mg} /$ day hydrocortisone or $8 \mathrm{mg} /$ day dexamethasone (or equivalent doses of other glucocorticoids) (Bacuzzi et al. 2017). If the patient exhibits tachycardia and increased blood pressure, propranolol can then be used to control these comorbidities.

Hyperfunctioning lung metastases are found to be more sensitive to ${ }^{131}$ I therapy than those of bone, in which radiation therapy is an excellent alternative used to relieve symptoms (Qiu et al. 2015). In addition, since a small number of patients are accompanied by liver metastasis, which is less ${ }^{131} \mathrm{I}$-avid, preliminary debulking of a large liver metastasis by percutaneous interstitial laser photocoagulation treatment followed by 131I therapy could achieve effective management (Guglielmi et al. 1999).

\section{Others}

Except for etiologies mentioned above, thyrotoxicosis induced by ATC, HCC and FVPTC have also been described (Kumar et al. 2005, Bommireddipalli et al. 2010, Ruggeri et al. 2013, Rees et al. 2015, Daroszewski et al. 2018). Additionally, painless thyroiditis-induced thyrotoxicosis has been reported to be associated with PTC (Valentini et al. 2016). Moreover, subacute thyroiditis associated with PTC has been found to mainly happened 


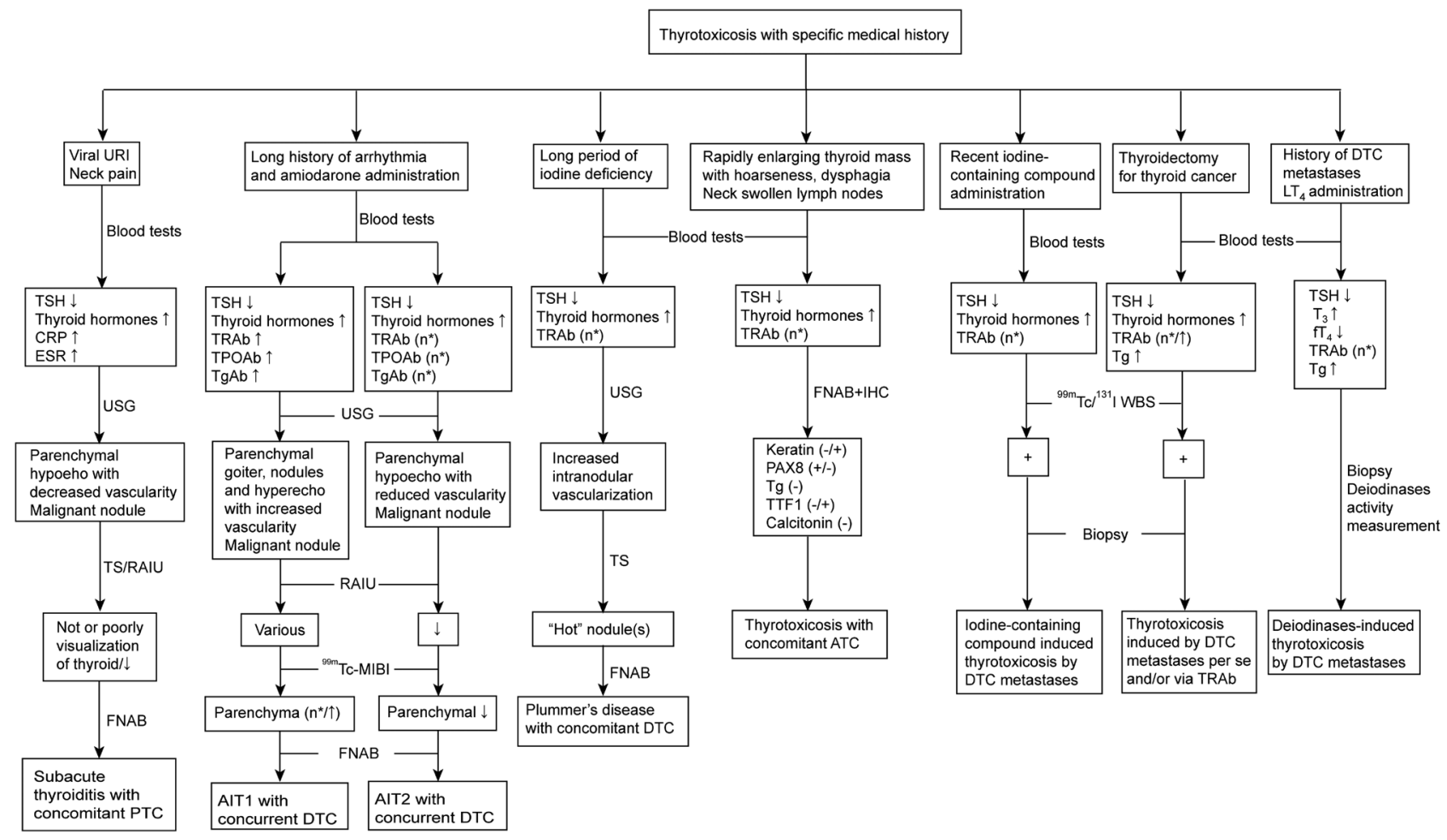

Figure 2

Algorithm for differential diagnoses of thyrotoxicosis with concomitant thyroid cancer in patients with specific medical history. AIT, amiodarone-induced thyrotoxicosis; ATC, anaplastic thyroid cancer; CRP, C-reactive protein; DTC, differentiated thyroid cancer; ESR, erythrocyte sedimentation rate; FNAB, fine-needle aspiration biopsy; $\mathrm{fT}_{4}$, free tetraiodothyronine; IHC, immunohistochemistry; $\mathrm{n}^{*}$, normal; PAX8, paired box gene 8; PTC, papillary thyroid cancer; RAIU, radioiodine uptake; $\mathrm{T}_{3}$, triiodomethylamine; 99mTc, 99mTc-pertechnetate; 99mTc-MIBI, 99mTc-sestamibi; Tg, thyroglobulin; TgAb, thyroglobulin antibody; TPOAb, thyroperoxidase antibody; TRAb, thyrotrophin receptor antibody; TS, thyroid scan; TSH, thyrotrophin; TTF1, thyroid transcription factor 1; URI, upper respiratory infection; USG, ultrasonography; WBS, whole-body scan.

in older female and the tumors' size occurred in subacute thyroiditis varies from $0.05 \mathrm{~cm}$ to $1.2 \mathrm{~cm}$ (Gul et al. 2018). The prevalence of PTC occurring in subacute thyroiditis is $4.4 \%$ regarding a study with 137 patients, which may be much higher than previous finding of $0.43 \%(5 / 1152)$ (Nishihara et al. 2008, Gul et al. 2018).

\section{Mechanism}

The rapid growth of the primary tumor may cause nonspecific thyroiditis, which has been deemed as the current mechanism of ATC induced thyrotoxicosis. However, reported cases of thyrotoxicosis associated with ATC show that the etiologies are non-specific, such as ATC associated with Graves' disease, autonomous thyroid nodules, and silent thyroiditis (Papapetrou \& Jackson 1975, Mazzaferri et al. 1977, Mazzaferri 2000, Phillips et al. 2007), and the underlying mechanism for thyrotoxicosis with concomitant ATC remains unclear.

HCC of the thyroid is an infrequent neoplasm, and rarely trap iodine. HCC induces thyrotoxicosis primarily because of a base substitution at codon 677. This TSHR mutant shows constitutive activity of cAMP, which may then be responsible for thyrotoxicosis (Russo et al. 1999). Thyroid cancer associated with scintigraphic 'hot' lesion may be explained by the presence of an incidental focus of nonfunctioning cancer cells coexisting within or close to the hyperfunctioning benign nodule or rarely, due to hyperfunctioning cancer cells per se.

For the mechanism of thyrotoxicosis with concurrent FVPTC, activation of the cAMP signal transduction system followed by the mutation of the TR gene, which is now thought to cause thyrotoxicosis, has been demonstrated in a great number of autonomously hyperfunctioning thyroid nodules (Bommireddipalli et al. 2010).

The mechanism of painless thyroiditis may be due to high dietary iodine intake (Caturegli et al. 2014). Cellular damage because of reactive alterations in stromal cells secondary to chronic inflammation has been recognized as the underlying mechanism of DTC development in patients with Hashimoto's thyroiditis (Farrell et al. 2017). (c) 2019 Society for Endocrinology Published by Bioscientifica Ltd. Printed in Great Britain 
Although viral infections and genetic factors are assumed to be related to the etiologies of subacute thyroiditis (Luotola et al. 1998), the pathogenesis of subacute thyroiditis with concomitant DTC has not been illuminated.

\section{Diagnosis}

Patients with thyrotoxicosis accompanied by ATC usually present symptoms of thyrotoxicosis with neck swelling due to a rapidly enlarging thyroid mass. Elevated free thyroid hormones and suppressed TSH can also be found (Daroszewski et al. 2018). Thyroid ultrasonography provides rapid evaluation of the primary thyroid tumor, allows assessment of the involvement of central and lateral lymph node basins, and assists in evaluating airway patency. Neck and chest CT should also be performed to assess the extent of disease. If accessible, ${ }^{18} \mathrm{~F}$-FDG PET/CT is particularly valuable in evaluating metastases.

Only approximately 5\% of HCC show 'hot' nodular lesions on the ${ }^{99 \mathrm{~m} T c-p e r t e c h n e t a t e}$ thyroid scan, and less than $10 \%$ of HCC take up radioiodine. Furthermore, a discordance uptake in HCC exists between 99mTcpertechnetate and radioiodine (Wong et al. 2003). In some cases of HCC, elevated thyroglobulin levels have been found, which could reflect recurrence of the malignancy. 99mTc-MIBI has been shown to be taken up by HCC, and the $99 \mathrm{~m}$ Tc-MIBI whole-body scan has been reported to be a sensitive marker for detecting metastases in those patients with elevated thyroglobulin (Yen et al. 1994). In addition, ${ }^{111}$ In labeled octreotide scan has been utilized to investigate HCC since 1998 (Gulec et al. 1998).

The final diagnosis of FVPTC reported are based on postoperative pathological examination, since the features of thyrotoxicosis induced by FVPTC are similar to those in benign AFTNs (Wong et al. 2003, Smallridge et al. 2012, Rees et al. 2015).

Elevated levels of TPOAb and decreased RAIU can generally be found in painless thyroiditis with concurrent DTC. Ultrasonography demonstrates diffuse hypoechoic pattern in the thyroid gland, which made it impossible to differentiate nodular with irregular

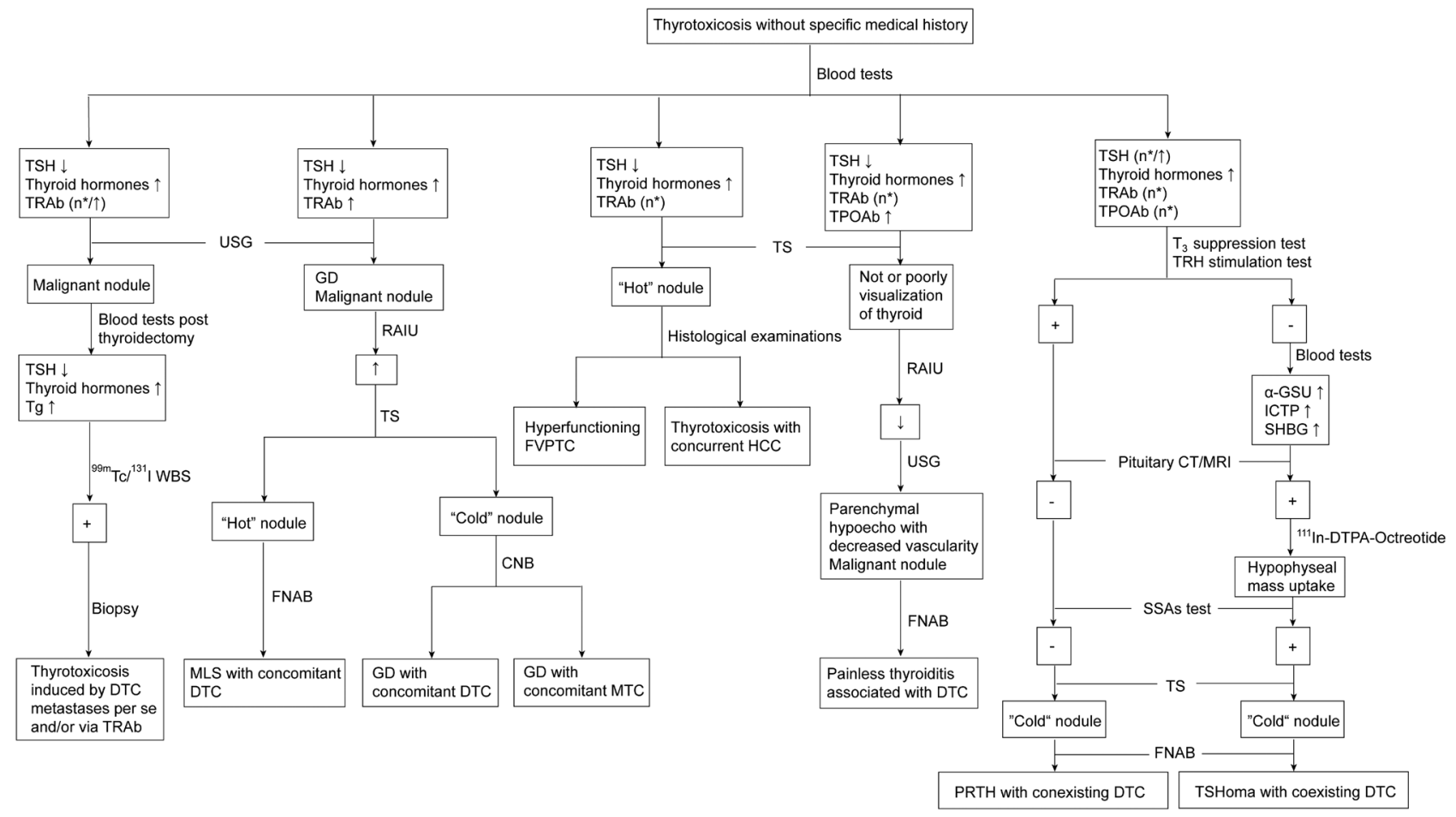

Figure 3

Algorithm for differential diagnoses of thyrotoxicosis with concomitant thyroid cancer in patients without specific medical history. $\alpha$-GSU, $\alpha$-glycoprotein; CNB, core needle biopsy; CT, computed tomography; DTC, differentiated thyroid cancer; FNAB, fine-needle aspiration biopsy; FNAC, fine-needle aspiration cytology; FVPTC, follicular variant of papillary thyroid carcinoma; GD, Graves' disease; HCC, Hürthle cell carcinoma; ICTP, telopeptide of type I collagen; MLS, Marine-Lenhart Syndrome; MTC, medullary thyroid cancer; PRTH, pituitary resistance to thyroid hormone; RAIU, radioiodine uptake; SHBG, sex-hormone-binding globulin; SSAs, somatostatin receptor analogs; $\mathrm{T}_{3}$, triiodomethylamine; $99 \mathrm{mTc}$, 99mTc-pertechnetate; Tg, thyroglobulin; TPOAb, thyroperoxidase antibody; TRAb, thyrotrophin receptor antibody; TRH, thyrotropic hormone-releasing hormone; TS, thyroid scan; TSH, thyrotrophin; USG, ultrasonography; WBS, whole-body scan. 
Table 1 Recommendations on the strategies for the management of thyrotoxicosis with concomitant thyroid cancer regarding each etiology.

Etiology

GD with concomitant DTC

GD with concomitant MTC

MLS with concomitant DTC

Plummer's disease with concomitant DTC

AIT1 with concurrent DTC

AIT2 with concurrent DTC

TSHoma with coexisting DTC

PRTH with coexisting DTC

lodine-containing compound induced thyrotoxicosis by DTC metastases

Thyrotoxicosis induced by DTC metastases per se and/ or via TRAb

Deiodinases-induced thyrotoxicosis by DTC metastases

Thyrotoxicosis with concomitant ATC

Thyrotoxicosis with concurrent HCC Hyperfunctioning FVPTC

\section{Diagnosis}

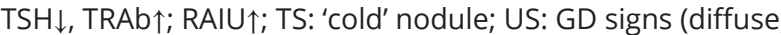
bilateral and isthmic goiter, heterogeneous and hypoechogenicity parenchyma with hypervascularization in CDF) and malignant nodule signs (irregular margins of hypoechoic nodule with calcifications, taller than wide shape, evidence of ETE); nodule FNAB (+)

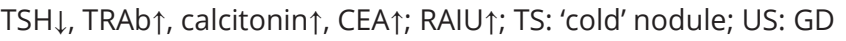
and malignant nodule signs

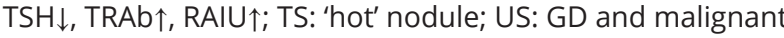
nodule signs; nodule FNAC $(+)$

Long period of iodine deficiency, TSH $\downarrow$, TRAb $(n *)$; TS: 'hot' nodule(s); US: normal echogenicity with increased intranodular vascularization; CT/MRI: metastases/substernal goiter; nodule FNAB (+)

Long history of arrhythmia and amiodarone administration; TSH $\downarrow$, TRA $\uparrow \uparrow, T P O A b \uparrow, T g A b \uparrow ;$ US: malignant nodule signs and parenchymal goiter, nodules and hyperecho with increased vascularity; $99 \mathrm{mTC}-\mathrm{MIBI}$ : normal/increased parenchymal uptake

Long history of arrhythmia and amiodarone administration; $\operatorname{TSH} \downarrow, \operatorname{TRA} b\left(n^{*}\right), \operatorname{TPOAb}\left(n^{*}\right), \operatorname{TgAb}\left(n^{*}\right)$; RAIU $\downarrow ;$ US: parenchymal hypoecho with reduced vascularity and malignant nodule; $99 \mathrm{mTc}-\mathrm{MIBI}$ : decreased parenchymal uptake

TSH $(n * / \uparrow), \operatorname{TRAb}\left(n^{*}\right), \operatorname{TPOAb}\left(n^{*}\right), \alpha-\mathrm{GSU} \uparrow$, ICTP $\uparrow$, SHBG $\uparrow ; T_{3}$ suppression test (-), TRH stimulation test (-); pituitary CT/MRI (+); ${ }^{111}$ In-DTPA-Octreotide: uptake in hypophyseal mass; SSAs test $(+)$; TS: 'cold' nodule; nodule FNAB (+)

TSH $(n * / \uparrow), \operatorname{TRAb}(n *)$, TPOAb $(n *), T$ suppression test $(+)$, TRH stimulation test (+); pituitary CT/MRI (-); SSAs test (-); TS: 'cold' nodule; similar biochemical results in relatives; nodule FNAB (+)

Recent iodine-containing compound administration, thyroid surgery history (+/-); TSH $\downarrow$, TRAb $(n *), T g \uparrow ; ~ C T / M R I$ : metastases; $99 \mathrm{mT}$ T-pertechnetate/131| WBS (+); metastases biopsy (+)

Thyroid surgery history (+/-); TSH $\downarrow$, TRAb $(n * / \uparrow), T g \uparrow ;$ CT/MRI: metastases; $99 \mathrm{mT}$ c-pertechnetate/131| WBS $(+)$; metastases biopsy (+)

History of DTC, levothyroxine administration; $\mathrm{TSH} \downarrow, \mathrm{T}_{3} \uparrow$,

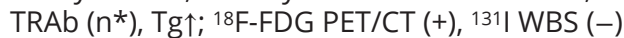

Rapid growth of neck mass; TSH $\downarrow$, TRAb $(n *) ; 18$ F-FDG PET/CT $(+)$; nodule FNAB + IHC: Keratin $(-/+)$, PAX8 (+/-), Tg $(-)$, TTF1 (-/+), Calcitonin (-)

TSH $\downarrow$, TRAb ( $\left.n^{*}\right)$;TS: 'hot' nodule; 99mTc-MIBI: nodule uptake;

111In-DTPA-Octreotide: nodule uptake

TSH $\downarrow$, TRAb $(n *) ; T S:$ 'hot' nodule; nodule FNAC (+)

\section{Therapy}

Surgery assisted by ATDs, beta-blockers, potassium iodine, corticosteroids, and cholestyramine

131I administration for unresectable metastases

Surgery assisted by ATDs and beta-blockers

Adjuvant therapy (radiation therapy and molecular targeted therapy)

Surgery with euthyroidism by

ATDs and beta-blockers

Subsequent ${ }^{131}$ | administration if necessary

Surgery with euthyroidism by

ATDs

131| administration for unresectable metastases

Discontinue amiodarone if possible

Surgery assisted by ATDs, beta-blockers, potassium perchlorate, corticosteroids, and lithium carbonate alone or combination

Plasmapheresis for emergency

SSAs, ATDs and beta-blockers before surgery

Pituitary adenomectomy and thyroidectomy

Thyroidectomy assisted by PTU

The levothyroxine therapy mimicking preoperative hormonal pattern

TRIAC and dopamine agonists alone or in combination

Stop intaking exogenous iodine-containing compound if possible

Thyroidectomy with possible metastasectomy

131| therapy assisted by ATDs, corticosteroids and betablockers for unresectable metastases

Debulking less ${ }^{131} \mid$-avid metastases

TKIs (Lenvatinib and Sorafenib)

Surgery assisted by ATDs and beta-blockers if necessary

Radiation therapy, chemotherapy, chemoradiation, TKIs (Sorafenib, Lenvatinib) and Fosbretabulin for unresectable ATC
C) 2019 Society for Endocrinology Published by Bioscientifica Ltd. Printed in Great Britain 
Table 1 Continued.

\begin{tabular}{|c|c|c|}
\hline Etiology & Diagnosis & Therapy \\
\hline $\begin{array}{l}\text { Painless thyroiditis associated } \\
\text { with DTC }\end{array}$ & $\begin{array}{l}\text { TSH } \downarrow, \text { TRAb }\left(n^{*}\right), \text { TPOAb } \uparrow \text {; RAIU } \downarrow \text {; US: parenchymal hypoecho } \\
\text { with decreased vascularity and malignant nodule; nodule } \\
\text { FNAB (+) }\end{array}$ & $\begin{array}{l}\text { Surgery after controlling } \\
\text { thyrotoxicosis with beta- } \\
\text { blockers }\end{array}$ \\
\hline $\begin{array}{l}\text { Subacute thyroiditis with } \\
\text { concomitant PTC }\end{array}$ & $\begin{array}{l}\mathrm{TSH} \downarrow ; \mathrm{CRP} \uparrow, \mathrm{ESR} \uparrow ; \text { TS: not or poorly visualization, RAIU } \downarrow ; \text { US: } \\
\text { parenchymal hypoecho and malignant nodule; FNAB (+) }\end{array}$ & $\begin{array}{l}\text { Surgery after anti-inflammatory } \\
\text { medications }\end{array}$ \\
\hline
\end{tabular}

$\alpha$-GSU, a-glycoprotein; AIT, amiodarone-induced thyrotoxicosis; ATC, anaplastic thyroid cancer; ATDs, anti-thyroid drugs; CDF, color Doppler flow; CEA, carcinoembryonic antigen; CRP, C-reactive protein; CT, computed tomography; DTC, differentiated thyroid cancer; ESR, erythrocyte sedimentation rate;

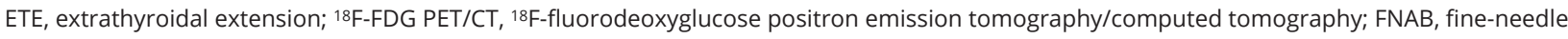
aspiration biopsy; FNAC, fine-needle aspiration cytology; FVPTC, follicular variant of papillary thyroid carcinoma; GD, Graves' disease; HCC, Hürthle cell carcinoma; ICTP, telopeptide of type I collagen; IHC, immunohistochemistry; MLS, Marine-Lenhart Syndrome; MRI, magnetic resonance imaging; MTC, medullary thyroid cancer; $\mathrm{n}$, normal; PAX8, paired box gene 8; PRTH, pituitary resistance to thyroid hormone; PTU, propylthiouracil; RAIU, radioiodine uptake; RRDTC, radioiodine refractory differentiated thyroid cancer; SHBG, sex-hormone-binding globulin; SSAs, somatostatin receptor analogs; $\mathrm{T}_{3}$, triiodomethylamine; 99mTc-MIBI, 99mTc-sestamibi; Tg, thyroglobulin; TgAb, thyroglobulin antibody; TKIs, tyrosine kinase inhibitors; TPOAb, thyroperoxidase antibody; TRAb, thyrotrophin receptor antibody; TRH, thyrotropic hormone releasing hormone; TRIAC, triiodothyroacetic acid; TS, thyroid scan; TSH, thyrotrophin; TSHoma, TSH-secreting pituitary adenoma; TTF1, thyroid transcription factor 1; US, ultrasonography; WBS, whole-body scan.

borders and microcalcification from inflammatory lesion. It is recommended to get another ultrasonography examination when the symptoms have resolved and laboratory values have recovered in order to rule out an underlying nodular disease (Nishihara et al. 2008). In cases with indeterminate thyroid nodule, FNAB is recommended (Valentini et al. 2016).

Swelling with pain in the thyroid gland are the clinical finding in patients of subacute thyroiditis associated with DTC. Elevated C-reactive protein, erythrocyte sedimentation rate, $\mathrm{FT}_{4}$, and decreased TSH are commonly found (Nishihara et al. 2008, Gul et al. 2018). Not or poorly visualization thyroid in thyroid scan, as well as low RAIU are helpful to confirm the diagnosis of subacute thyroiditis (Fatourechi et al. 2003). It is difficult to point out the coexistence of DTC with subacute thyroiditis, because unspecific focal with indefinite borders or diffuse hypoechoic parenchyma at initial ultrasonography could obscure the coexistence of tumor, however, microcalcifications in parenchyma and unnormal cervical lymph nodes are clues of suspicious malignancy in the presence of adjacent hypoechoic areas. Color Doppler flow is not particularly helpful for differential diagnosis between subacute thyroiditis and tumor, because approximately $30 \%$ of PTC are hypovascular and subacute thyroiditis only in the recovery phase presents slightly increased vascularization (Hiromatsu et al. 1999, Chan et al. 2003). Bekir Ucan et al. considered that elastography may assist in the diagnosis and monitoring of subacute thyroiditis as well as deciding biopsy requirement in subacute thyroiditis coexistent with suspicious nodules (Ucan et al. 2014). Owing to the characteristics of subacute thyroiditis with concurrent DTC, postponing assessment of the nodule until a complete recovery from subacute thyroiditis is sensible. In addition, FNAB is indispensable in cases of lesions which are seen as a focal mass mimicking thyroid cancer.

\section{Treatment}

The treatment criteria for thyrotoxicosis associated with ATC has not yet been established due to its rare incidence, rapid progression, poor response to therapies and dismal prognosis. Even with intervention, survival benefits are limited (Kumar et al. 2005, Phillips et al. 2007, Daroszewski et al. 2018). ATDs and beta-blockers are generally administered to control thyrotoxicosis (Daroszewski et al. 2018). Management, however, remains most challenging for the primary tumor. Although in appropriate cases complete resection of tumor is the single intervention that improves survival, rather than debulking (Akaishi et al. 2011), the clinical presentation of ATC limits surgical treatment in the majority of patients (Heymann et al. 2005, Phillips et al. 2007, Daroszewski et al. 2018). Owing to improvement of central compartment palliation, surgery should be considered even in the presence of distant disease (Smallridge et al. 2012).

Reduced mortality and improved survival have been shown in postoperative radiation therapy with a radiation dose of $>45$ Gy (Pierie et al. 2002). For patients who are not suitable for surgery, the primary tumor, as well as metastases, can be treated palliatively with external beam irradiation (Heymann et al. 2005, Kumar et al. 2005).

Chemoradiation has been shown to be superior to radiation alone (Sugitani et al. 2012), and doxorubicin is the most commonly used drug. To improve the outcome, clinical trials have been conducted with several combinations. The commonly used combinations are (c) 2019 Society for Endocrinology Published by Bioscientifica Ltd. Printed in Great Britain 
taxanes (paclitaxel or docetaxel) and/or anthracycline (doxorubicin) and/or platins (cisplatin or carboplatin), in combination with radiotherapy. Although the prognosis for most patients with ATC continues to be poor, multimodality therapy can significantly improve the survival (Akaishi et al. 2011).

With the best knowledge of ATC tumor biology, there are a few new drugs tested for ATC treatment, which may also be used in ATC patients associated with thyrotoxicosis. Sorafenib and fosbretabulin have been used in the treatment of ATC but show limited efficacy (Sosa et al. 2014, Thomas et al. 2014). Lenvatinib, another multikinase inhibitor, has demonstrated clinical activity and manageable toxicities in patients with ATC (Tahara et al. 2017).

Total thyroidectomy should be offered in patients with HCC. The efficacy of ${ }^{131}$ I treatment is unclear because most HCC do not trap iodine. Patients with thyrotoxicosis induced by FVPTC can be treated with ATDs to attenuate symptoms and signs of thyrotoxicosis. In general, patients with FVPTC-induced thyrotoxicosis undergo near/total thyroidectomy; and ${ }^{131} \mathrm{I}$ is subsequently administered not only for postsurgical thyroid remnant ablation and/or metastases therapy but for convenient periodical surveillance as well (Bommireddipalli et al. 2010, Rees et al. 2015).

Thyrotoxicosis induced by painless thyroiditis is deemed to be caused by the preformed thyroid hormones released from the destructed follicular. Therefore, treatment with beta-blockers, rather than ATDs, is recommended. After clinical recovery, thyroidectomy can be performed to remove the primary tumor (Farrell et al. 2017).

Subacute thyroiditis is self-limited disease and often resolves spontaneously or may improve with anti-inflammatory medications (Jhaveri et al. 2003). Subsequent thyroidectomy with neck dissection if needed is the choice for thyroid cancer (Nishihara et al. 2008, Ucan et al. 2014).

\section{Conclusion}

The understanding of the causal relationship between thyrotoxicosis and thyroid cancer is critical for accurate diagnosis and appropriate treatment. After discussion of underlying mechanisms in terms of each etiology, efficient management means are recommended, yielding diagnostic mind mapping flowcharts with regard to the presence (Fig. 2) or absence (Fig. 3) of specific medical history and refined therapeutic strategies (Table 1).
For Graves' disease, MLS, AIT, Plummer's disease, central hyperthyroidism, painless thyroiditis or subacute thyroiditis associated with DTC, Graves' disease with concurrent MTC and primary hyperfunctioning thyroid cancer (HCC or FVPTC), surgery after controlling thyrotoxicosis with medications remains the first choice. If unresectable DTC metastases exist, adjuvant modalities major in ${ }^{131}$ I therapy are needed. For hyperfunctioning DTC metastases, medications-aided 131I therapy after thyroidectomy with possible metastasectomy remains a mainstay. In radioiodine refractory thyroid cancer patients who manifest thyrotoxicosis simultaneously, debulking approaches and molecular targeted therapy are promising to control thyrotoxicosis and prolong survival. For ATC accompanied by thyrotoxicosis, since ATDs and surgery merely relieve symptoms, radiotherapy, chemotherapy as well as neoadjuvant therapy are necessary.

\section{Declaration of interest}

The authors declare that there is no conflict of interest that could be perceived as prejudicing the impartiality of this review.

\section{Funding}

This study was sponsored by the National Natural Science Foundation of China (grant number 81671711) and the Shanghai Key Discipline of Medical Imaging (grant number 2017ZZ02005).

\section{References}

Aguilar Diosdado M, Escobar-Jimenez L, Fernandez Soto ML, Garcia Curiel A \& Escobar-Jimenez F 1991 Hyperthyroidism due to familial pituitary resistance to thyroid hormone: successful control with 3,5 , 3 ' triiodothyroacetic associated to propranolol. Journal of Endocrinological Investigation 14 663-668. (https://doi.org/10.1007/ BF03347890)

Ahmed S, Van Gelder IC, Wiesfeld AC, Van Veldhuisen DJ \& Links TP 2011 Determinants and outcome of amiodarone-associated thyroid dysfunction. Clinical Endocrinology 75 388-394. (https://doi. org/10.1111/j.1365-2265.2011.04087.x)

Akaishi J, Sugino K, Kitagawa W, Nagahama M, Kameyama K, Shimizu K, Ito K \& Ito K 2011 Prognostic factors and treatment outcomes of 100 cases of anaplastic thyroid carcinoma. Thyroid $\mathbf{2 1}$ 1183-1189. (https://doi.org/10.1089/thy.2010.0332)

Alzahrani AS, Ceresini G \& Aldasouqi SA 2012 Role of ultrasonography in the differential diagnosis of thyrotoxicosis: a noninvasive, costeffective, and widely available but underutilized diagnostic tool. Endocrine Practice 18 567-578. (https://doi.org/10.4158/EP11170.RA)

Amlashi FG \& Tritos NA 2016 Thyrotropin-secreting pituitary adenomas: epidemiology, diagnosis, and management. Endocrine 52 427-440. (https://doi.org/10.1007/s12020-016-0863-3)

Bacuzzi A, Dionigi G, Guzzetti L, De Martino AI, Severgnini P \& Cuffari S 2017 Predictive features associated with thyrotoxic storm and management. Gland Surgery 6 546-551. (https://doi. org/10.21037/gs.2017.07.01)

Barakate MS, Agarwal G, Reeve TS, Barraclough B, Robinson B \& Delbridge LW 2002 Total thyroidectomy is now the preferred option (c) 2019 Society for Endocrinology Published by Bioscientifica Ltd. Printed in Great Britain 
for the surgical management of Graves' disease. ANZ Journal of Surgery 72 321-324. (https://doi. org/10.1046/j.1445-2197.2002.02400.x)

Bartalena L, Bogazzi F, Chiovato L, Hubalewska-Dydejczyk A, Links TP \& Vanderpump M 20182018 European Thyroid Association (ETA) guidelines for the management of amiodarone-associated thyroid dysfunction. European Thyroid Journal 7 55-66. (https://doi. org/10.1159/000486957)

Bartalena L, Grasso L, Brogioni S, Aghini-Lombardi F, Braverman LE \& Martino E 1994 Serum interleukin-6 in amiodarone-induced thyrotoxicosis. Journal of Clinical Endocrinology and Metabolism 78 423-427. (https://doi.org/10.1210/jcem.78.2.8106631)

Basharat R, Bukhari MH, Saeed S \& Hamid T 2011 Comparison of fine needle aspiration cytology and thyroid scan in solitary thyroid nodule. Pathology Research International 2011 754041. (https://doi. org/10.4061/2011/754041)

Beck-Peccoz P, Persani L, Mannavola D \& Campi I 2009 Pituitary tumours: TSH-secreting adenomas. Best Practice and Research. Clinical Endocrinology and Metabolism 23 597-606. (https://doi.org/10.1016/j. beem.2009.05.006)

Bianco AC, Salvatore D, Gereben B, Berry MJ \& Larsen PR 2002 Biochemistry, cellular and molecular biology, and physiological roles of the iodothyronine selenodeiodinases. Endocrine Reviews 23 38-89. (https://doi.org/10.1210/edrv.23.1.0455)

Biyi A, Zaimi S \& Doudouh A 2016 Functioning metastases from thyroid papillary carcinoma in bone. Journal of Nuclear Medicine Technology 44 253-254. (https://doi.org/10.2967/jnmt.116.174573)

Bogazzi F, Bartalena L, Gasperi M, Braverman LE \& Martino E 2001 The various effects of amiodarone on thyroid function. Thyroid $\mathbf{1 1}$ 511-519. (https://doi.org/10.1089/105072501300176471)

Bogazzi F, Bartalena L \& Martino E 2010 Approach to the patient with amiodarone-induced thyrotoxicosis. Journal of Clinical Endocrinology and Metabolism 95 2529-2535. (https://doi.org/10.1210/jc.20100180)

Bogazzi F, Tomisti L, Bartalena L, Aghini-Lombardi F \& Martino E 2012 Amiodarone and the thyroid: a 2012 update. Journal of Endocrinological Investigation 35 340-348. (https://doi. org $/ 10.3275 / 8298)$

Bommireddipalli S, Goel S, Gadiraju R, Paniz-Mondolfi A \& Depuey EG 2010 Follicular variant of papillary thyroid carcinoma presenting as a toxic nodule by I-123 scintigraphy. Clinical Nuclear Medicine $\mathbf{3 5}$ 770-775. (https://doi.org/10.1097/RLU.0b013e3181e4dc7f)

Brierley J, Tsang R, Simpson WJ, Gospodarowicz M, Sutcliffe S \& Panzarella T 1996 Medullary thyroid cancer: analyses of survival and prognostic factors and the role of radiation therapy in local control. Thyroid 6 305-310. (https://doi.org/10.1089/thy.1996.6.305)

Calissendorff J \& Falhammar H 2017 Lugol's solution and other iodide preparations: perspectives and research directions in Graves' disease. Endocrine 58 467-473. (https://doi.org/10.1007/s12020-017-1461-8)

Calle-Pascual AL, Yuste E, Martin P, Aramendi T, Garcia-Maurino ML, Argente J, Catalan MJ, Uria J, Cabranes JA \& Charro AL 1991 Association of a thyrotropin-secreting pituitary adenoma and a thyroid follicular carcinoma. Journal of Endocrinological Investigation 14 499-502. (https://doi.org/10.1007/BF03346852)

Carle A, Knudsen N, Pedersen IB, Perrild H, Ovesen L, Rasmussen LB \& Laurberg P 2013 Determinants of serum T4 and T3 at the time of diagnosis in nosological types of thyrotoxicosis: a population-based study. European Journal of Endocrinology 169 537-545. (https://doi. org/10.1530/EJE-13-0533)

Cattaneo F 2000 Type II amiodarone-induced thyrotoxicosis and concomitant papillary cancer of the thyroid. European Journal of Endocrinology 143 823-824. (https://doi.org/10.1530/eje.0.1430823)

Caturegli P, De Remigis A \& Rose NR 2014 Hashimoto thyroiditis: clinical and diagnostic criteria. Autoimmunity Reviews 13 391-397. (https://doi.org/10.1016/j.autrev.2014.01.007)
Cerletty JM \& Listwan WJ 1979 Hyperthyroidism due to functioning metastatic thyroid carcinoma. Precipitation of thyroid storm with therapeutic radioactive iodine. JAMA 242 269-270. (https://doi. org/10.1001/jama.242.3.269)

Chan BK, Desser TS, Mcdougall IR, Weigel RJ \& Jeffrey RB 2003 Common and uncommon sonographic features of papillary thyroid carcinoma. Journal of Ultrasound in Medicine 22 1083-1090. (https:// doi.org/10.7863/jum.2003.22.10.1083)

Chantadisai M \& Kingpetch K 2014 Usefulness of 99MTc-pertechnetate whole body scan with neck and chest SPECT/CT for detection of post-surgical thyroid remnant and metastasis in differentiated thyroid cancer patients. Annals of Nuclear Medicine 28 674-682. (https://doi.org/10.1007/s12149-014-0864-3)

Danilovic DL, de Camargo RY, Castro G, Papadia C, Marui S \& Hoff AO 2015 Rapid control of T3 thyrotoxicosis in patients with metastatic follicular thyroid cancer treated with lenvatinib. Thyroid $\mathbf{2 5}$ 1262-1264. (https://doi.org/10.1089/thy.2015.0167)

Daroszewski J, Paczkowska K, Jawiarczyk-Przybylowska A, Bolanowski M \& Jelen M 2018 Anaplastic thyroid carcinoma with rapid thyrotoxicosis - a case report and the literature review. Endokrynologia Polska 69 28-31. (https://doi.org/10.5603/EP. a2018.0010)

De Los Santos ET, Starich GH \& Mazzaferri EL 1989 Sensitivity, specificity, and cost-effectiveness of the sensitive thyrotropin assay in the diagnosis of thyroid disease in ambulatory patients. Archives of Internal Medicine 149 526-532. (https://doi.org/10.1001/ archinte.149.3.526)

De Souza Meyer EL, Dora JM, Wagner MS \& Maia AL 2005 Decreased type 1 iodothyronine deiodinase expression might be an early and discrete event in thyroid cell dedifferentation towards papillary carcinoma. Clinical Endocrinology 62 672-678. (https://doi. org/10.1111/j.1365-2265.2005.02277.x)

Dulgeroff AJ, Geffner ME, Koyal SN, Wong M \& Hershman JM 1992 Bromocriptine and Triac therapy for hyperthyroidism due to pituitary resistance to thyroid hormone. Journal of Clinical Endocrinology and Metabolism 75 1071-1075. (https://doi. org/10.1210/jcem.75.4.1400873)

Elnaggar MN, Jbeili K, Nik-Hussin N, Kozhippally M \& Pappachan JM 2018 Amiodarone-induced thyroid dysfunction: a clinical update. Experimental and Clinical Endocrinology and Diabetes 126 333-341. (https://doi.org/10.1055/a-0577-7574)

Farrell E, Heffron C, Murphy M, O'Leary G \& Sheahan P 2017 Impact of lymphocytic thyroiditis on incidence of pathological incidental thyroid carcinoma. Head and Neck 39 122-127. (https://doi. org/10.1002/hed.24544)

Fatourechi V, Aniszewski JP, Fatourechi GZ, Atkinson EJ \& Jacobsen SJ 2003 Clinical features and outcome of subacute thyroiditis in an incidence cohort: Olmsted County, Minnesota, study. Journal of Clinical Endocrinology and Metabolism 88 2100-2105. (https://doi. org/10.1210/jc.2002-021799)

Filetti S, Belfiore A, Amir SM, Daniels GH, Ippolito O, Vigneri R \& Ingbar SH 1988 The role of thyroid-stimulating antibodies of Graves' disease in differentiated thyroid cancer. New England Journal of Medicine 318 753-759. (https://doi.org/10.1056/ NEJM198803243181206)

Fiore E \& Vitti P 2012 Serum TSH and risk of papillary thyroid cancer in nodular thyroid disease. Journal of Clinical Endocrinology and Metabolism 97 1134-1145. (https://doi.org/10.1210/jc.2011-2735)

Franklyn JA \& Gammage MD 2007 Treatment of amiodarone-associated thyrotoxicosis. Nature Clinical Practice: Endocrinology and Metabolism 3 662-666. (https://doi.org/10.1038/ncpendmet0592)

Geliebter A, Brutsaert EF \& Surks MI 2017 An unusual case of metastatic functional thyroid carcinoma with a remarkable treatment response to radioactive iodine. Journal of the Endocrine Society 1 1440-1444. (https://doi.org/10.1210/js.2017-00296) (c) 2019 Society for Endocrinology Published by Bioscientifica Ltd. Printed in Great Britain 
Gilbert J 2017 Thyrotoxicosis - investigation and management. Clinical Medicine 17 274-277. (https://doi.org/10.7861/ clinmedicine.17-3-274)

Goichot B, Leenhardt L, Massart C, Raverot V, Tramalloni J, Iraqi H \& Consensus Work-Group 2018 Diagnostic procedure in suspected Graves' disease. Annales d'Endocrinologie 79 608-617. (https://doi. org/10.1016/j.ando.2018.08.002)

Guglielmi R, Pacella CM, Dottorini ME, Bizzarri GC, Todino V, Crescenzi A, Rinaldi R, Panunzi C, Rossi Z, Colombo L, et al. 1999 Severe thyrotoxicosis due to hyperfunctioning liver metastasis from follicular carcinoma: treatment with (131)I and interstitial laser ablation. Thyroid 9 173-177. (https://doi.org/10.1089/thy.1999.9.173)

Gul N, Uzum AK, Selcukbiricik ÖS, Yegen G, Tanakol R \& Aral F 2018 Prevalence of papillary thyroid cancer in subacute thyroiditis patients may be higher than it is presumed: retrospective analysis of 137 patients. Radiology and Oncology 52 257-262. (https://doi. org/10.2478/raon-2018-0027)

Gulec SA, Serafini AN, Sridhar KS, Peker KR, Gupta A, Goodwin WJ, Sfakianakis GN \& Moffat FL 1998 Somatostatin receptor expression in Hurthle cell cancer of the thyroid. Journal of Nuclear Medicine 39 243-245.

Habra MA, Hijazi R, Verstovsek G \& Marcelli M 2004 Medullary thyroid carcinoma associated with hyperthyroidism: a case report and review of the literature. Thyroid 14 391-396. (https://doi. org/10.1089/105072504774193249)

Hahm JR, Lee MS, Min YK, Lee MK, Kim KW, Nam SJ, Yang JH \& Chung JH 2001 Routine measurement of serum calcitonin is useful for early detection of medullary thyroid carcinoma in patients with nodular thyroid diseases. Thyroid 11 73-80. (https://doi. org/10.1089/10507250150500694)

Haq M, Hyer S, Flux G, Cook G \& Harmer C 2007 Differentiated thyroid cancer presenting with thyrotoxicosis due to functioning metastases. British Journal of Radiology $\mathbf{8 0}$ e38-e43. (https://doi.org/10.1259/ bjr/52032397)

Hegedüs L, Paschke R, Krohn K \& Bonnema SJ 2016 Chapter 90 Multinodular goiter. In Endocrinology: Adult and Pediatric, 7th ed. Eds JL Jameson, LJ De Groot, DM De Kretser, LC Giudice, AB Grossman, S Melmed, JT Potts \& GC Weir. Philadelphia, PA, USA: W.B. Saunders.

Haugen BR, Alexander EK, Bible KC, Doherty GM, Mandel SJ, Nikiforov YE, Pacini F, Randolph GW, Sawka AM, Schlumberger M, et al. 20162015 American Thyroid Association management guidelines for adult patients with thyroid nodules and differentiated thyroid cancer: the American Thyroid Association Guidelines Task Force on Thyroid Nodules and Differentiated Thyroid Cancer. Thyroid 26 1-133. (https://doi.org/10.1089/thy.2015.0020)

Heymann RS, Brent GA \& Hershman JM 2005 Anaplastic thyroid carcinoma with thyrotoxicosis and hypoparathyroidism. Endocrine Practice 11 281-284. (https://doi.org/10.4158/EP.11.4.281)

Hiromatsu Y, Ishibashi M, Miyake I, Soyejima E, Yamashita K, Koike N \& Nonaka K 1999 Color Doppler ultrasonography in patients with subacute thyroiditis. Thyroid 9 1189-1193. (https://doi.org/10.1089/ thy.1999.9.1189)

Houghton SG, Farley DR, Brennan MD, Van Heerden JA, Thompson GB \& Grant CS 2004 Surgical management of amiodarone-associated thyrotoxicosis: Mayo Clinic experience. World Journal of Surgery 28 1083-1087. (https://doi.org/10.1007/s00268-004-7599-6)

Inaba H, Suzuki S, Takeda T, Kobayashi S, Akamizu T \& Komatsu M 2012 Amiodarone-induced thyrotoxicosis with thyroid papillary cancer in multinodular goiter: case report. Medical Principles and Practice 21 190-192. (https://doi.org/10.1159/000333697)

Jhaveri K, Shroff MM, Fatterpekar GM \& Som PM 2003 CT and MR imaging findings associated with subacute thyroiditis. American Journal of Neuroradiology 24 143-146.

Kaderli RM, Fahrner R, Christ ER, Stettler C, Fuhrer J, Martinelli M, Vogt A \& Seiler CA 2016 Total thyroidectomy for amiodarone- induced thyrotoxicosis in the hyperthyroid state. Experimental and Clinical Endocrinology and Diabetes 124 45-48. (https://doi. org/10.1055/s-0035-1565094)

Kang AS, Grant CS, Thompson GB \& Van Heerden JA 2002 Current treatment of nodular goiter with hyperthyroidism (Plummer's disease): surgery versus radioiodine. Surgery 132 916-923; discussion 923. (https://doi.org/10.1067/msy.2002.128691)

Karamanakos SN, Markou KB, Panagopoulos K, Karavias D, Vagianos CE, Scopa CD, Fotopoulou V, Liava A \& Vagenas K 2010 Complications and risk factors related to the extent of surgery in thyroidectomy. Results from 2043 procedures. Hormones 9 318-325. (https://doi. org/10.14310/horm.2002.1283)

Kiatpanabhikul P, Shuangshoti S, Chantra K, Navicharern P, Kingpetch K, Houngngam N \& Snabboon T 2017 A case of coexistence of TSH/GH-secreting pituitary tumor and papillary thyroid carcinoma: challenges in pathogenesis and management. Journal of Clinical Neuroscience 41 78-80. (https://doi.org/10.1016/j. jocn.2017.02.050)

Kim C, Baek JH, Ha E, Lee JH, Choi YJ, Song DE, Kim JK, Chung KW, Kim WB \& Shong YK 2017 Ultrasonography features of medullary thyroid cancer as predictors of its biological behavior. Acta Radiologica 58 414-422. (https://doi.org/10.1177/0284185116656491)

Kishida M, Otsuka F, Kataoka H, Yokota K, Oishi T, Yamauchi T, Doihara H, Tamiya T, Mimura Y, Ogura T, et al. 2000 Hyperthyroidism in a patient with TSH-producing pituitary adenoma coexisting with thyroid papillary adenocarcinoma. Endocrine Journal 47 731-738. (https://doi.org/10.1507/endocrj.47.731)

Krohn K, Führer D, Bayer Y, Eszlinger M, Brauer V, Neumann S \& Paschke R 2005 Molecular pathogenesis of euthyroid and toxic multinodular goiter. Endocrine Reviews 26 504-524. (https://doi. org/10.1210/er.2004-0005)

Kumar V, Blanchon B, Gu X, Fowler M, Scarborough D, Nathan CO \& Yaturu S 2005 Anaplastic thyroid cancer and hyperthyroidism. Endocrine Pathology 16 245-250. (https://doi.org/10.1385/ EP:16:3:245)

Kunawudhi A, Promteangtrong C \& Chotipanich C 2016 A case report of hyperfunctioning metastatic thyroid cancer and rare I-131 avid liver metastasis. Indian Journal of Nuclear Medicine 31 210-214. (https://doi.org/10.4103/0972-3919.183616)

Kurita S, Ando H, Kaneko S \& Takamura T 2008 Intra-thyroid blood flow in Plummer's disease. Internal Medicine 47 1065-1066. (https://doi. org/10.2169/internalmedicine.47.1091)

Liu M, Chai L, Luo Q, Ruan M, Cheng L, Lv Z \& Chen L 2017 99mTcpertechnetate-avid metastases from differentiated thyroid cancer are prone to benefit from 131I therapy: a prospective observational study. Medicine 96 e7631. (https://doi.org/10.1097/

MD.0000000000007631)

Lombardi M, Tonacchera M \& Macchia E 2018 A new case of MarineLenhart syndrome with a papillary thyroid carcinoma. Clinical Case Reports 6 2299-2302. (https://doi.org/10.1002/ccr3.1769)

Lorberboym M \& Mechanick JI 1996 Accelerated thyrotoxicosis induced by iodinated contrast media in metastatic differentiated thyroid carcinoma. Journal of Nuclear Medicine 37 1532-1535.

Losa M, Magnani P, Mortini P, Persani L, Acerno S, Giugni E, Songini C, Fazio F, Beck-Peccoz P \& Giovanelli M 1997 Indium-111 pentetreotide single-photon emission tomography in patients with TSH-secreting pituitary adenomas: correlation with the effect of a single administration of octreotide on serum TSH levels. European Journal of Nuclear Medicine 24 728-731. (https://doi.org/10.1007/ BF00879659)

Luotola K, Hyoty H, Salmi J, Miettinen A, Helin H \& Pasternack A 1998 Evaluation of infectious etiology in subacute thyroiditis - lack of association with coxsackievirus infection. APMIS 106 500-504. (https://doi.org/10.1111/j.1699-0463.1998.tb01378.x)

Mackie GC \& Shulkin BL 2005 Amiodarone-induced hyperthyroidism in a patient with functioning papillary carcinoma of the thyroid and https://erc.bioscientifica.com

https://doi.org/10.1530/ERC-19-0129 (c) 2019 Society for Endocrinology Published by Bioscientifica Ltd. Printed in Great Britain 
extensive hepatic metastases. Thyroid 15 1337-1340. (https://doi. org/10.1089/thy.2005.15.1337)

Malaguarnera R, Morcavallo A \& Belfiore A 2012 The insulin and igf-I pathway in endocrine glands carcinogenesis. Journal of Oncology 2012 635614. (https://doi.org/10.1155/2012/635614)

Mannavola D, Persani L, Vannucchi G, Zanardelli M, Fugazzola L, Verga U, Facchetti M \& Beck-Peccoz P 2005 Different responses to chronic somatostatin analogues in patients with central hyperthyroidism. Clinical Endocrinology 62 176-181. (https://doi. org/10.1111/j.1365-2265.2004.02192.x)

Maqdasy S, Benichou T, Dallel S, Roche B, Desbiez F, Montanier N, Batisse-Lignier M \& Tauveron I 2018 Issues in amiodarone-induced thyrotoxicosis: update and review of the literature. Annales d'Endocrinologie 80 54-60. (https://doi.org/10.1016/j. ando.2018.05.001)

Marine D \& Lenhart CH 1911 Pathological anatomy of exophthalmic goiter. Archives of Internal Medicine VIII 265-316. (https://doi. org/10.1001/archinte.1911.00060090002001)

Mazzaferri EL 1990 Thyroid cancer and Graves' disease. Journal of Clinical Endocrinology and Metabolism 70 826-829. (https://doi. org/10.1210/jcem-70-4-826)

Mazzaferri EL 2000 Thyroid cancer and Graves' disease: the controversy ten years later. Endocrine Practice 6 221-225. (https://doi.org/10.4158/ EP.6.2.221)

Mazzaferri EL, Young RL, Oertel JE, Kemmerer WT \& Page CP 1977 Papillary thyroid carcinoma: the impact of therapy in 576 patients. Medicine 56 171-196. (https://doi.org/10.1097/00005792-19770500000001)

Miyauchi A, Takamura Y, Ito Y, Miya A, Kobayashi K, Matsuzuka F, Amino N, Toyoda N, Nomura E \& Nishikawa M 2008 3,5,3'-Triiodothyronine thyrotoxicosis due to increased conversion of administered levothyroxine in patients with massive metastatic follicular thyroid carcinoma. Journal of Clinical Endocrinology and Metabolism 93 2239-2242. (https://doi.org/10.1210/jc.2007-2282)

Narayana SK, Woods DR \& Boos CJ 2011 Management of amiodaronerelated thyroid problems. Therapeutic Advances in Endocrinology and Metabolism 2 115-126. (https://doi.org/10.1177/2042018811398516)

Naswa N, Das CJ, Sharma P, Karunanithi S, Bal C \& Kumar R 2012 Ectopic pituitary adenoma with empty sella in the setting of MEN-1 syndrome: detection with 68Ga-DOTANOC PET/CT. Japanese Journal of Radiology 30 783-786. (https://doi.org/10.1007/s11604-012-0117-0)

Ness-Abramof R, Ishay A, Harel G, Sylvetzky N, Baron E, Greenman Y \& Shimon I 2007 TSH-secreting pituitary adenomas: follow-up of 11 cases and review of the literature. Pituitary 10 307-310. (https://doi. org/10.1007/s11102-007-0020-3)

Ngalob QG \& Isip-Tan IT 2013 Thyroid cancer in Plummer's disease. BMJ Case Reports 2013 bcr2013008909. (https://doi.org/10.1136/bcr2013-008909)

Nishihara E, Amino N \& Miyauchi A 2010 Fractionated radioiodine therapy for hyperthyroidism caused by widespread metastatic follicular thyroid carcinoma. Thyroid 20 569-570. (https://doi. org/10.1089/thy.2009.0460)

Nishihara E, Hirokawa M, Ohye H, Ito M, Kubota S, Fukata S, Amino N \& Miyauchi A 2008 Papillary carcinoma obscured by complication with subacute thyroiditis: sequential ultrasonographic and histopathological findings in five cases. Thyroid 18 1221-1225. (https://doi.org/10.1089/thy.2008.0096)

Panzer C, Beazley R \& Braverman L 2004 Rapid preoperative preparation for severe hyperthyroid Graves' disease. Journal of Clinical Endocrinology and Metabolism 89 2142-2144. (https://doi. org/10.1210/jc.2003-031981)

Papapetrou PD \& Jackson IM 1975 Thyrotoxicosis due to 'silent' thyroiditis. Lancet 1 361-363. (https://doi.org/10.1016/S01406736(75)91278-7)

Paragliola RM, Lovicu RM, Locantore P, Senes P, Concolino P, Capoluongo E, Pontecorvi A \& Corsello SM 2011 Differentiated thyroid cancer in two patients with resistance to thyroid hormone. Thyroid 21 793-797. (https://doi.org/10.1089/thy.2010.0233)

Pazaitou-Panayiotou K, Michalakis K \& Paschke R 2012 Thyroid cancer in patients with hyperthyroidism. Hormone and Metabolic Research 44 255-262. (https://doi.org/10.1055/s-0031-1299741)

Pellegriti G, Belfiore A, Giuffrida D, Lupo L \& Vigneri R 1998 Outcome of differentiated thyroid cancer in Graves' patients. Journal of Clinical Endocrinology and Metabolism 83 2805-2809. (https://doi. org/10.1210/jcem.83.8.4997)

Pellegriti G, Mannarino C, Russo M, Terranova R, Marturano I, Vigneri R \& Belfiore A 2013 Increased mortality in patients with differentiated thyroid cancer associated with Graves' disease. Journal of Clinical Endocrinology and Metabolism 98 1014-1021. (https://doi. org/10.1210/jc.2012-2843)

Perticone F, Pigliaru F, Mariotti S, Deiana L, Furlani L, Mortini P \& Losa M 2015 Is the incidence of differentiated thyroid cancer increased in patients with thyrotropin-secreting adenomas? Report of three cases from a large consecutive series. Thyroid 25 417-424. (https://doi.org/10.1089/thy.2014.0222)

Phillips JS, Pledger DR \& Hilger AW 2007 Rapid thyrotoxicosis in anaplastic thyroid carcinoma. Journal of Laryngology and Otology $\mathbf{1 2 1}$ 695-697. (https://doi.org/10.1017/S0022215106005330)

Pierie JP, Muzikansky A, Gaz RD, Faquin WC \& Ott MJ 2002 The effect of surgery and radiotherapy on outcome of anaplastic thyroid carcinoma. Annals of Surgical Oncology 9 57-64. (https://doi. org/10.1245/aso.2002.9.1.57)

Piga M, Cocco MC, Serra A, Boi F, Loy M \& Mariotti S 2008 The usefulness of $99 \mathrm{mTc}$-sestaMIBI thyroid scan in the differential diagnosis and management of amiodarone-induced thyrotoxicosis. European Journal of Endocrinology 159 423-429. (https://doi. org/10.1530/EJE-08-0348)

Porterfield JR, Thompson GB, Farley DR, Grant CS \& Richards ML 2008 Evidence-based management of toxic multinodular goiter (Plummer's disease). World Journal of Surgery 32 1278-1284. (https://doi. org/10.1007/s00268-008-9566-0)

Preece J, Grodski S, Yeung M, Bailey M \& Serpell J 2014 Thyrotoxicosis does not protect against incidental papillary thyroid cancer. Surgery 156 1153-1156. (https://doi.org/10.1016/j.surg.2014.04.025)

Qiu ZL, Shen CT \& Luo QY 2015 Clinical management and outcomes in patients with hyperfunctioning distant metastases from differentiated thyroid cancer after total thyroidectomy and radioactive iodine therapy. Thyroid 25 229-237. (https://doi.org/10.1089/thy.2014.0233)

Rees DO, Anthony VA, Jones K \& Stephens JW 2015 Follicular variant of papillary thyroid carcinoma: an unusual cause of thyrotoxicosis. $B M J$ Case Reports 2015 bcr2014207091. (https://doi.org/10.1136/bcr-2014207091)

Rosario F, Marques AR, Roque L, Rodrigues R, Ferreira TC, Limbert E, Sobrinho L \& Leite V 2005 Metastatic follicular carcinoma associated with hyperthyroidism. Clinical Nuclear Medicine 30 79-82. (https:// doi.org/10.1097/00003072-200502000-00001)

Ross DS, Burch HB, Cooper DS, Greenlee MC, Laurberg P, Maia AL, Rivkees SA, Samuels M, Sosa JA, Stan MN, et al. 20162016 American Thyroid Association guidelines for diagnosis and management of hyperthyroidism and other causes of thyrotoxicosis. Thyroid $\mathbf{2 6}$ 1343-1421. (https://doi.org/10.1089/thy.2016.0229)

Ruggeri RM, Campennì A, Giovinazzo S, Saraceno G, Vicchio TM, Carlotta D, Cucinotta MP, Micali C, Trimarchi F, Tuccari G, et al. 2013 Follicular variant of papillary thyroid carcinoma presenting as toxic nodule in an adolescent: coexistent polymorphism of the TSHR and Gs $\alpha$ genes. Thyroid 23 239-242. (https://doi.org/10.1089/ thy.2012.0279)

Russo D, Tumino S, Arturi F, Vigneri P, Grasso G, Pontecorvi A, Filetti S \& Belfiore A 1997 Detection of an activating mutation of the thyrotropin receptor in a case of an autonomously hyperfunctioning thyroid insular carcinoma. Journal of Clinical Endocrinology and Metabolism 82 735-738. (https://doi.org/10.1210/jcem.82.3.3838) 
Russo D, Wong MG, Costante G, Chiefari E, Treseler PA, Arturi F, Filetti S \& Clark OH 1999 A Val 677 activating mutation of the thyrotropin receptor in a Hurthle cell thyroid carcinoma associated with thyrotoxicosis. Thyroid 9 13-17. (https://doi.org/10.1089/ thy.1999.9.13)

Saad A, Falciglia M, Steward DL \& Nikiforov YE 2004 Amiodaroneinduced thyrotoxicosis and thyroid cancer: clinical, immunohistochemical, and molecular genetic studies of a case and review of the literature. Archives of Pathology and Laboratory Medicine 128 807-810. (https://doi.org/10.1043/1543-2165(2004)128<807:ATA TCC $>2.0 . \mathrm{CO} ; 2)$

Salvatori M, Saletnich I, Rufini V, Dottorini ME, Corsello SM, Troncone L \& Shapiro B 1998 Severe thyrotoxicosis due to functioning pulmonary metastases of well-differentiated thyroid cancer. Journal of Nuclear Medicine 39 1202-1207.

Scherer T, Wohlschlaeger-Krenn E, Bayerle-Eder M, Passler C, ReinerConcin A, Krebs M \& Gessl A 2013 A Case of simultaneous occurrence of Marine-Lenhart syndrome and a papillary thyroid microcarcinoma. BMC Endocrine Disorders 13 16. (https://doi org/10.1186/1472-6823-13-16)

Seidlin SM, Marinelli LD \& Oshry E 1946 Radioactive iodine therapy; effect on functioning metastases of adenocarcinoma of the thyroid. JAMA 132 838-847. (https://doi.org/10.3322/canjclin.40.5.299)

Sharma A 2017 Marine-Lenhart syndrome in two adolescents, including one with thyroid cancer: a case series and review of the literature. Journal of Pediatric Endocrinology and Metabolism 30 1237-1243. (https://doi.org/10.1515/jpem-2017-0223)

Shigemasa C, Abe K, Taniguchi S, Mitani Y, Ueda Y, Adachi T, Urabe K, Tanaka T, Yoshida A \& Mashiba H 1987 Lower serum free thyroxine (T4) levels in painless thyroiditis compared with Graves' disease despite similar serum total T4 levels. Journal of Clinical Endocrinology and Metabolism 65 359-363. (https://doi.org/10.1210/jcem-65-2-359)

Smallridge RC, Ain KB, Asa SL, Bible KC, Brierley JD, Burman KD, Kebebew E, Lee NY, Nikiforov YE, Rosenthal MS, et al. 2012 American Thyroid Association guidelines for management of patients with anaplastic thyroid cancer. Thyroid 22 1104-1139. (https://doi.org/10.1089/thy.2012.0302)

Smith JJ, Chen X, Schneider DF, Nookala R, Broome JT, Sippel RS, Chen H \& Solorzano CC 2013 Toxic nodular goiter and cancer: a compelling case for thyroidectomy. Annals of Surgical Oncology 20 1336-1340. (https://doi.org/10.1245/s10434-012-2725-4)

Solomon B \& Rischin D 2012 Progress in molecular targeted therapy for thyroid cancer: vandetanib in medullary thyroid cancer. Journal of Clinical Oncology 30 119-121. (https://doi.org/10.1200/ JCO.2011.37.8638)

Sosa JA, Elisei R, Jarzab B, Balkissoon J, Lu SP, Bal C, Marur S, Gramza A, Yosef RB, Gitlitz B, et al. 2014 Randomized safety and efficacy study of fosbretabulin with paclitaxel/carboplatin against anaplastic thyroid carcinoma. Thyroid 24 232-240. (https://doi.org/10.1089/ thy.2013.0078)

Stocker DJ \& Burch HB 2003 Thyroid cancer yield in patients with Graves' disease. Minerva Endocrinologica 28 205-212.

Su VY, Hu YW, Chou KT, Ou SM, Lee YC, Lin EY, Chen TJ, Tzeng CH \& Liu CJ 2013 Amiodarone and the risk of cancer: a nationwide population-based study. Cancer 119 1699-1705. (https://doi. org/10.1002/cncr.27881)

Sudheer Ahamed PS \& Mathew A 2009 A case of amiodarone-induced thyrotoxicosis: a diagnostic and therapeutic dilemma. Sultan Qaboos University Medical Journal 9 319-323.

Sugitani I, Miyauchi A, Sugino K, Okamoto T, Yoshida A \& Suzuki S 2012 Prognostic factors and treatment outcomes for anaplastic thyroid carcinoma: ATC Research Consortium of Japan cohort study of 677 patients. World Journal of Surgery 36 1247-1254. (https://doi. org/10.1007/s00268-012-1437-z)

Sundaraiya S, Dizdarevic S, Miles K, Quin J, Williams A, Wheatley T \& Zammitt C 2009 Unusual initial manifestation of metastatic follicular carcinoma of the thyroid with thyrotoxicosis diagnosed by technetium Tc $99 \mathrm{~m}$ pertechnetate scan: case report and review of literature. Endocrine Practice 15 458-462. (https://doi.org/10.4158/ EP08300.CRR)

Sundaresh V, Brito JP, Thapa P, Bahn RS \& Stan MN 2017 Comparative effectiveness of treatment choices for Graves' hyperthyroidism: a historical cohort study. Thyroid 27 497-505. (https://doi. org/10.1089/thy.2016.0343)

Suzuki S, Shigematsu S, Inaba H, Takei M, Takeda T \& Komatsu M 2011 Pituitary resistance to thyroid hormones: pathophysiology and therapeutic options. Endocrine 40 366-371. (https://doi.org/10.1007/ s12020-011-9538-2)

Tahara M, Kiyota N, Yamazaki T, Chayahara N, Nakano K, Inagaki L, Toda K, Enokida T, Minami H, Imamura Y, et al. 2017 Lenvatinib for anaplastic thyroid cancer. Frontiers in Oncology 7 25. (https://doi. org/10.3389/fonc.2017.00025)

Takano T, Miyauchi A, Ito Y \& Amino N 2006 Thyroxine to triiodothyronine hyperconversion thyrotoxicosis in patients with large metastases of follicular thyroid carcinoma. Thyroid 16 615-618. (https://doi.org/10.1089/thy.2006.16.615)

Tan J, Zhang G, Xu W, Meng Z, Dong F, Zhang F, Jia Q \& Liu X 2009 Thyrotoxicosis due to functioning metastatic follicular thyroid carcinoma after twelve I-131 therapies. Clinical Nuclear Medicine 34 615-619. (https://doi.org/10.1097/RLU.0b013e3181b06b2d)

Thomas L, Lai SY, Dong W, Feng L, Dadu R, Regone RM \& Cabanillas ME 2014 Sorafenib in metastatic thyroid cancer: a systematic review. Oncologist 19 251-258. (https://doi.org/10.1634/ theoncologist.2013-0362)

Tjornstrand A \& Nystrom HF 2017 DIAGNOSIS of ENDOCRINE DISEASE: Diagnostic approach to TSH-producing pituitary adenoma. European Journal of Endocrinology 177 R183-R197. (https://doi. org/10.1530/EJE-16-1029)

Tonnelier A, De Filette J, De Becker A, Deweer S \& Velkeniers B 2017 Successful pretreatment using plasma exchange before thyroidectomy in a patient with amiodarone-induced thyrotoxicosis. European Thyroid Journal 6 108-112. (https://doi.org/10.1159/000453578)

Ucan B, Delibasi T, Cakal E, Arslan MS, Bozkurt NC, Demirci T, Ozbek M \& Sahin M 2014 Papillary thyroid cancer case masked by subacute thyroiditis. Arquivos Brasileiros de Endocrinologia e Metabologia $\mathbf{5 8}$ 851-854. (https://doi.org/10.1590/0004-2730000003222)

Uludag M, Aygun N, Ozel A, Yener Ozturk F, Karasu R, Ozguven BY, Citgez B, Mihmanli M \& Isgor A 2016 A rare presentation of autonomously functioning papillary thyroid cancer: malignancy in Marine-Lenhart syndrome nodule. Case Reports in Surgery 2016 8740405. (https://doi.org/10.1155/2016/8740405)

Valenti TM, Macchia E, Pisa R, Bucalo ML, Russo V, Colletti I, Compagno V, Abbadi V \& Donatelli M 1999 Toxic adenoma and papillary thyroid carcinoma in a patient with Graves' disease. Journal of Endocrinological Investigation 22 701-704. (https://doi.org/10.1007/ BF03343633)

Valentini RB, Macedo BM, Izquierdo RF \& Meyer EL 2016 Painless thyroiditis associated to thyroid carcinoma: role of initial ultrasonography evaluation. Archives of Endocrinology and Metabolism 60 178-182. (https://doi.org/10.1590/2359-3997000000104)

Van Der Molen AJ, Thomsen HS, Morcos SK \& Contrast Media Safety Committee, European Society of Urogenital Radiology (ESUR) 2004 Effect of iodinated contrast media on thyroid function in adults. European Radiology 14 902-907. (https://doi.org/10.1007/s00330-0042238-z)

Vinagre J, Borges F, Costa A, Alvelos MI, Mazeto G, Sobrinho-Simoes M \& Soares P 2014 Differentiated thyroid cancer in patients with resistance to thyroid hormone syndrome. A novel case and a review of the literature. Frontiers in Molecular Biosciences 1 10. (https://doi. org/10.3389/fmolb.2014.00010)

Weber KJ, Solorzano CC, Lee JK, Gaffud MJ \& Prinz RA 2006 Thyroidectomy remains an effective treatment option for Graves' https://erc bioscientifica com

https://doi.org/10.1530/ERC-19-0129 (c) 2019 Society for Endocrinology Published by Bioscientifica Ltd. Printed in Great Britain 
disease. American Journal of Surgery 191 400-405. (https://doi. org/10.1016/j.amjsurg.2005.10.043)

Wiersinga WM 2010 The role of thyroid hormone nuclear receptors in the heart: evidence from pharmacological approaches. Heart Failure Reviews 15 121-124. (https://doi.org/10.1007/s10741-008-9131-9)

Williams M \& Lo Gerfo P 2002 Thyroidectomy using local anesthesia in critically ill patients with amiodarone-induced thyrotoxicosis: a review and description of the technique. Thyroid 12 523-525. (https://doi.org/10.1089/105072502760143926)

Wong CP, Auyong TK \& Tong CM 2003 Thyrotoxicosis: a rare presenting symptom of Hurthle cell carcinoma of the thyroid. Clinical Nuclear Medicine 28 803-806. (https://doi.org/10.1097/01. rlu.0000089667.15648.e9)

Yamada S, Fukuhara N, Horiguchi K, Yamaguchi-Okada M, Nishioka H, Takeshita A, Takeuchi Y, Ito J \& Inoshita N 2014 Clinicopathological characteristics and therapeutic outcomes in thyrotropin-secreting pituitary adenomas: a single-center study of 90 cases. Journal of Neurosurgery 121 1462-1473. (https://doi.org/10.3171/2014.7.JNS1471)

Yang J, Liu S, Yang Z \& Shi YB 2017 Ectopic thyrotropin secreting pituitary adenoma concomitant with papillary thyroid carcinoma: case report. Medicine 96 e8912. (https://doi.org/10.1097/MD.0000000000008912)

Yano Y, Shibuya H, Kitagawa W, Nagahama M, Sugino K, Ito K \& Ito K 2007 Recent outcome of Graves' disease patients with papillary thyroid cancer. European Journal of Endocrinology 157 325-329. (https://doi.org/10.1530/EJE-07-0136)

Yen TC, Lin HD, Lee CH, Chang SL \& Yeh SH 1994 The role of technetium-99m sestamibi whole-body scans in diagnosing metastatic Hurthle cell carcinoma of the thyroid gland after total thyroidectomy: a comparison with iodine-131 and thallium-201 whole-body scans. European Journal of Nuclear Medicine 21 980-983. (https://doi.org/10.1007/BF00238123)

Yiu KH, Jim MH, Siu CW, Lee CH, Yuen M, Mok M, Shea YF, Fan K, Tse HF \& Chow WH 2009 Amiodarone-induced thyrotoxicosis is a predictor of adverse cardiovascular outcome. Journal of Clinical Endocrinology and Metabolism 94 109-114. (https://doi.org/10.1210/ jc.2008-1907)

Yoshimura Noh J, Mimura T, Kawano M, Hamada N \& Ito K 1997 Appearance of TSH receptor antibody and hyperthyroidism associated with metastatic thyroid cancer after total thyroidectomy. Endocrine Journal 44 855-859. (https://doi.org/10.1507/ endocri.44.855)

Zhu L, Zainudin SB, Kaushik M, Khor LY \& Chng CL 2016 Plasma exchange in the treatment of thyroid storm secondary to type II amiodarone-induced thyrotoxicosis. Endocrinology, Diabetes and Metabolism Case Reports 2016 160039. (https://doi.org/10.1530/EDM16-0039)

Received in final form 18 April 2019

Accepted 26 April 2019

Accepted Preprint published online 26 April 2019 (c) 2019 Society for Endocrinology Published by Bioscientifica Ltd. Printed in Great Britain 